AVALIAÇÃO CLÍNICO-PATOLÓGICA DA INTOXICAÇÃO CRÔNICA EXPERIMENTAL PELA Palicourea marcgravii e Palicourea aeneofusca em OVINOS no Distrito Federal.

Edson de Figueiredo Gaudêncio Barbosa ORIENTADOR: PROF. DR. MÁRCIO BOTELHO DE CASTRO

TRABALHO DE TESE SUBMETIDO AO PROGRAMA DE PÓS-GRADUAÇÃO, COMO PARTE DOS REQUISITOS NECESSÁRIOS À OBTENÇÃO DO GRAU DE DOUTOR EM SAÚDE ANIMAL.

\title{
Publicação 009/16
}

\author{
BRASÍLIA-DF
}

Dezembro/ 2016 
AVALIAÇÃO CLÍNICO-PATOLÓGICA DA INTOXICAÇÃO CRÔNICA EXPERIMENTAL DE CAPRINOS E OVINOS PELA Palicourea marcgravii $\mathrm{e}$ Palicourea aeneofusca.

TRABALHO DE TESE SUBMETIDO AO PROGRAMA DE PÓS-GRADUAÇÃO, COMO PARTE DOS REQUISITOS NECESSÁRIOS À OBTENÇÃO DO GRAU DE DOUTOR EM SAÚDE ANIMAL.

APROVADO POR:

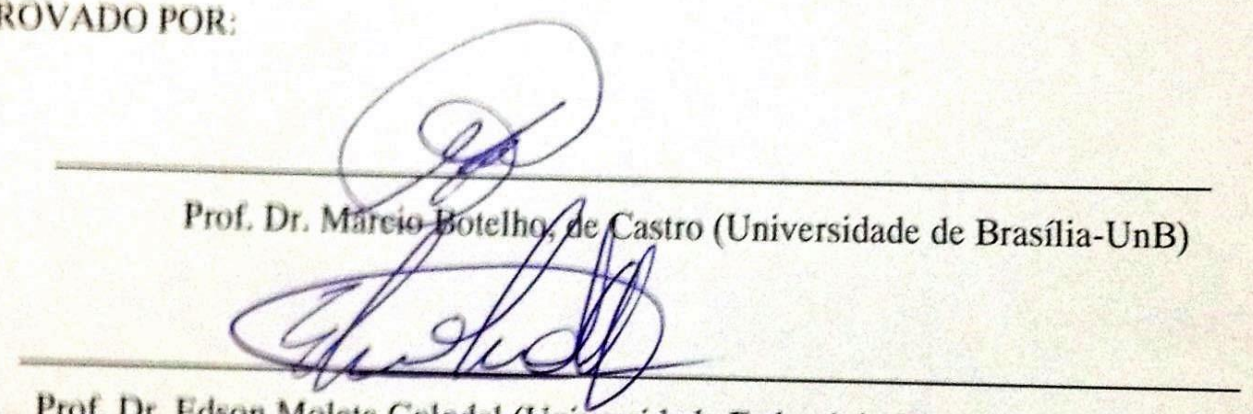

Prof. Dr. Edson Moleta Colodel (Universidade Federal do Mato Grosso-UFMT)

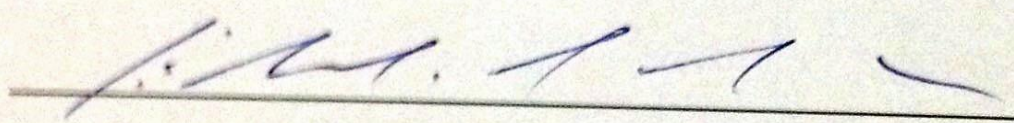

Prof. Dr. Eduardo Maurício Mendes de Rima (Universidade de Brasília-UnB)

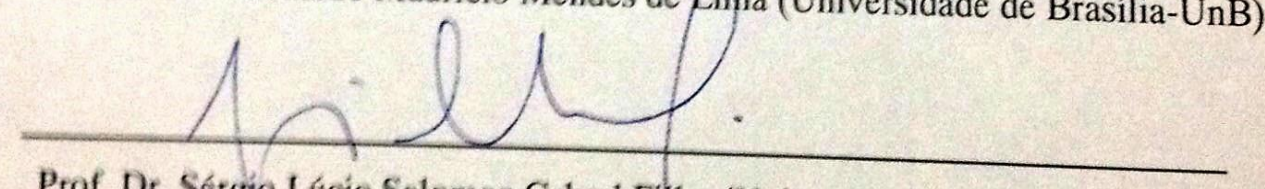

Prof. Dr. Sérgio Lácio Salomon Cabral Fitho (Universidade de Brasília-UnB)

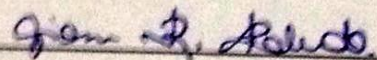

Prof. Dra. Giane Regina Paludo (Universidade de Brasília-UnB)

BRASíliA, 06 de dezembro de 2016. 


\section{REFERÊNCIA BIBLIOGRÁFICA E CATALOGAÇÃO}

BARbosa, E. F. G. AVALIAÇão ClíNiCO-PATOLÓGICA DA INTOXICAÇÃO CRÔNICA EXPERIMENTAL PELA Palicourea marcgravii e Palicourea aeneofusca em OVINOS no Distrito Federal. Brasília: Faculdade de Agronomia e Medicina Veterinária, Universidade de Brasília, 2016, 43 p. Tese de Doutorado.

Documento formal, autorizando reprodução desta tese de doutorado empréstimo ou comercialização, exclusivamente para fins acadêmicos, foi passado pelo autor a Universidade de Brasília e acha-se arquivado na secretaria do programa. O autor reserva para si os outros direitos autorais, de publicação. Nenhuma parte desta tese de doutorado pode ser reproduzida sem a autorização por escrito do autor. Citações são estimuladas, desde que citada à fonte.

\section{FICHA CATALOGRÁFICA}

Barbosa, Edson de Figueiredo Gaudêncio. AVALIAÇÃo CLÍNICOPATOLÓGICA DA INTOXICAÇÃO CRÔNICA EXPERIMENTAL PELA Palicourea marcgravii e Palicourea aeneofusca. EM OVINOS orientação de Márcio Botelho de Castro - Brasília, 2016. 43 p.: il.

Tese de Doutorado $(\mathrm{T})$ - Universidade de Brasília/Faculdade de Agronomia e Medicina Veterinária, 2016.

1. Palicourea marcgravii. 2.Palicourea aeneofusca. 3. Patologia. 4. Ovinos Intoxicação crônica experimental. 5. Clínico-patológica. BARBOSA, E. F. G. II. Título. 


\section{AGRADECIMENTOS}

Agradeço, primeiramente, a Deus, por ter abençoado os meus caminhos. Obrigado, Pai eterno, por ter me proporcionado saúde e a paz necessária, além de todos os recursos para chegar até aqui.

À minha esposa, à minha família em especial, minha amada mãe, Verônica de Figueiredo, pelo seu exemplo de esforço, dedicação, comprometimento com a nossa família. Sem esquecer de todo o auxílio proporcionado durante os momentos mais difíceis desta minha caminhada.

Um agradecimento especial para os meus cães, que sempre fazem a festa quando volto para casa, exausto, me ensinando que a vida é feita de bons momentos.

Ao professor Márcio Botelho de Castro, em especial, pela oportunidade, auxílio e orientação durante toda a realização do trabalho. Muito obrigado.

À CAPES pela bolsa concedida e a todo pessoal do Centro de Manejo de Ovinos da Fazenda Água Limpa da Unb, por todo apoio para a realização deste projeto. 
INTRODUÇÃO

OBJETIVOS.

CAPITULO 1

INTRODUÇÃO 9

MATERIAL E MÉTODOS 10

RESULTADOS 11

DISCUSSÃO E CONCLUSÃO .

FIGURA 1 e 2 16

QUADRO 1 17

REFERÊNCIAS 18

CAPITULO 2 22

INTRODUÇÃO 23

MATERIAL E MÉTODOS 24

RESULTADOS 25

DISCUSSÃO 27

CONCLUSÃO 33

REFERÊNCIAS 34

FIGURA 1 38

QUADRO 1 e 2 39

FIGURAS 2 a 4 41 


\section{INTRODUÇÃO}

No território brasileiro, em razão da grandeza territorial, a grande maioria das propriedades produtoras de animais tem como base alimentar dos seus rebanhos as pastagens, sejam elas plantadas ou nativas, criados extensivamente ou de forma semi-extensiva. Esse fato pode explicar o acesso ao consumo de plantas tóxicas pelos animais. Por isso há um aumento nos relatos de surtos de intoxicações por plantas em animais de produção no Brasil. Essas perdas influenciam negativamente a produtividade da pecuária nacional e, por isso, nos últimos anos houve um grande aumento na tentativa de desenvolvimento de novas pesquisas que busquem a caracterização do quadro clinico-patológico e da epidemiologia, para o desenvolvimento de técnicas na prevenção e combate a surtos de intoxicações por plantas.

$\mathrm{Na}$ atualidade, são conhecidas 12 plantas comprovadamente tóxicas causadoras de morte súbita em animais de produção. A Palicourea marcgravii é considerada a planta tóxica de interesse pecuário mais importante no Brasil, devido à extensa distribuição territorial, elevada toxicidade, boa palatabilidade e efeito acumulativo. Dentre as plantas tóxicas, a P. marcgravii apresenta a maior concentração de monofluoracetato em suas folhas, seguida pela $P$. aeneofusca que é encontrada no agreste e zona da mata de alguns estados do Nordeste. Está toxina causa um bloqueio no ciclo de Krebs, resultando em quadro de marcada insuficiência cardíaca aguda, principalmente quando o animal é estimulado a se movimentar.

Devido à elevada toxicidade da Palicourea marcgravii e da P. aeneofusca para animais de interesse pecuário, ainda não são bem conhecidas as doses mínimas necessárias para que ocorram surtos de intoxicação natural de animais a campo, especialmente quando há exposição crônica às plantas, em condições de pequena disponibilidade para os animais. A ovinocultura e a caprinocultura nacional têm aumentado em importância e expandindo suas áreas de criação. Dessa forma, torna-se importante reconhecer os entraves ao seu desenvolvimento, dentre eles a intoxicações por plantas que podem infringir severas perdas econômicas aos plantéis. 


\section{OBJETIVOS}

GERAL:

Caracterizar os efeitos da exposição crônica experimental de caprinos a Palicourea marcgravii e de ovinos a Palicourea aeneofusca e Palicourea marcgravii.

\section{ESPECÍFICOS:}

- Avaliar as alterações cardíacas em caprinos cronicamente intoxicados por $P$. marcgravii;

- Determinar as alterações clínico e patológicas em ovinos cronicamente intoxicados por P. marcgravii e P. aeneofusca;

- Comparar os padrões de lesões e a distribuição destas entre as espécies caprina e ovina. 


\title{
Capitulo 01
}

Alterações cardiotóxicas em caprinos cronicamente intoxicados por Palicourea marcgravii

\author{
Edson de F. G. Barbosa ${ }^{1}$ e Márcio B. Castro ${ }^{1}$
}

\begin{abstract}
Barbosa E.F.G. \& Castro M.B. 2016. [Cardiotoxic changes in goats chronically intoxicated by Palicourea marcgravii.] Pesquisa Veterinária Brasileira 00(0):00. Laboratório de Patologia Veterinária, Hospital Veterinário, Universidade de Brasília, Via L4 Norte, Cx. Postal 4508, Brasília, DF 70910-970, Brazil. E-mail: mbcastro@unb.br
\end{abstract}

Palicourea marcgravii is considered the main poison plant of livestock interest in Brazil that contains monofluoroacetic acid in its composition. Due to its high toxicity, only the acute form of intoxication that results in the sudden death of animals is well recognized, but the chronic form can occur causing marked cardiotoxicity. To investigate cardiac pathological changes caused by chronic $P$. marcgravii ingestion, 6 goats received daily doses of $0.2 \mathrm{~g} / \mathrm{kg}$ of body weight of fresh leaves of the plant for 28 days. The intoxicated animals had areas that were focally extensive and diffuse with marked myocardial pallor, which corresponded to marked vacuolization and cardiomyocyte swelling. The scarce necrosis of cardiac fibers was observed in the areas evaluated, evidenced by the absence of cardiomyocyte immunolabeling by the anti-troponin $C$ antibody. Chronic poisoning of goats by P. marcgravii produces clinicopathological changes and death of the animals due to severe cardiotoxic effect. Livestock animals kept in extensive breeding production and presence of the plant in the forests, chronic exposure to low doses of $P$. marcgravii should be considered in the differential diagnosis of ruminant death.

Index Terms: Troponin C, cardiotoxicity, imunohistochemistry, Caprine, Palicourea marcgravii.

RESUMO.- Palicourea marcgravii é considerada a principal planta tóxica de interesse pecuário no Brasil que contêm o ácido monofluoracético em sua composição. Devido a sua alta toxicidade, é bem reconhecida apenas a forma aguda da intoxicação que resulta na morte súbita dos animais, porém a forma crônica pode ocorrer causando marcante cardiotoxicidade. Para investigar as alterações patológicas cardíacas causadas pela ingestão crônica de $P$. marcgravii, foram utilizados 6 caprinos que receberam a dose diária de $0,2 \mathrm{~g} / \mathrm{kg}$ de peso corporal de folhas frescas da planta por 28 dias. Os animais intoxicados apresentaram áreas focalmente extensas a difusas de marcada palidez do miocárdio que correspondiam a marcante vacuolização e tumefação de cardiomiócitos. A necrose escassa de fibras cardíacas foi observada nas áreas avaliadas, evidenciada pela ausência de imunomarcação de cardiomiócitos pelo anticorpo antitroponina C. Esse trabalho demonstrou que a intoxicação crônica de caprinos por P. marcgravii produz alterações clínico-patológicas e morte dos animais devido ao acentuado efeito cardiotóxico. Em locais de criação extensiva de animais de produção e há presença da planta nas matas, a exposição crônica à baixas doses de $P$. marcgravii deve ser considerada no diagnóstico diferencial da morte de ruminantes.

Termos de indexação: Troponina C, intoxicação, imunohistoquímica, monofluoracetato.

\footnotetext{
${ }^{1}$ Hospital Veterinário, Universidade de Brasília (UnB), Laboratório de Patologia Veterinária, Via L4 Norte, Cx.

Postal 4508, Brasília, DF 70910-970, Brasil. *Autor para correspondência: mbcastro@unb.br
} 


\section{INTRODUÇÃO}

Em várias partes do mundo, plantas tóxicas que contêm monofluoracetato (MFA) causam morte súbitas de animais quando consumidas. Dentre essas plantas, se destacam principalmente a Dichapetalum spp. na África, os gêneros Palicourea, Amorimia e Arrabiedea na América do Sul, e Acacia sp., Oxylobium sp., Nemcia sp. e Gastrolobium sp. na Austrália, (Vickery \& Vickery 1972, Lee et al. 2014).

A Palicourea marcgravii é considerada a principal planta tóxica do Brasil, causando anualmente a morte de milhares de ruminantes (Nogueira et al. 2010, Furlan et al. 2012, Pessoa et al. 2013). Esta planta apresenta a maior concentração de MFA nas folhas dentre as espécies de plantas causadoras de morte súbita no país (Lee et al. 2012, Cook et al. 2014, Lee et al. 2014). Devido a sua extensa distribuição territorial, elevada toxicidade, boa palatabilidade e efeito acumulativo, pouca quantidade da planta na região pode ser suficiente para que ocorram casos de intoxicação (Tokarnia \& Dobereiner, 1986, Tokarnia et al. 2002, Tokarnia et al. 2012). Experimentalmente, foi comprovado que a administração de subdoses de $0,2 \mathrm{~g} / \mathrm{kg}$ de peso vivo de folhas frescas da planta administradas a caprinos, por até 38 dias produziu severas lesões no miocárdio e morte dos animais (Reis jr et al. 2009, Barbosa et al. 2015).

Apesar da elevada toxicidade e da importância da $P$. marcgravii como causa de morte súbita em ruminantes, pouco se conhece sobre as lesões cardíacas em animais com exposição prolongada a subdoses da planta. O objetivo deste trabalho foi investigar experimentalmente as alterações cardíacas em caprinos cronicamente intoxicados por Palicourea marcgravii. 


\section{MATERIAL E MÉTODOS}

Foi realizada no Centro de manejo de ovinos (CMO), da Fazenda Águas Limpas FAL-UnB, 1556'S e 47ำ56'W, a 1080 m de altitude, Brasília, DF. A intoxicação crônica experimental por $P$. marcgravii em 9 caprinos adultos com a dose diária por via oral de $0,2 \mathrm{~g} / \mathrm{kg}$ de folhas frescas da planta por 28 dias e três animais foram utilizados como controle. Os caprinos foram mantidos em baias coletivas cobertas, alimentados com silagem de milho e concentrado comercial para caprinos e água fresca ad libitum. As plantas foram coletadas em propriedades no entornodo Distrito Federal, onde havia histórico de morte súbita de bovinos. Após coletadas eram separadas somente as folhas e armazenadas em sacos plásticos lacrados, em refrigerador a $4^{\circ} \mathrm{C}$. Ao término do experimento, os caprinos que não morreram intoxicados e o grupo controle, foram submetidos à eutanasia com barbitúrico intravenoso de ação ultracurta, segundo os procedimentos recomendados para ruminantes (CFMV, 2013).

Todos os animais foram submetidos a necropsias e amostras cardíaca dos átrios, ventrículos e septo interventricular foram individualmente fixadas em solução de formalina tamponada a $10 \%$, processadas para histologia, incluídas em parafina e coradas com hematoxilina-eosina (HE) e tricrômico de masson. Seç̧ões histológicas de cada uma das regiões cardíacas dos 9 caprinos foram submetidas à técnica da imunoperoxidase, utilizando o anticorpo primário monoclonal anti-troponina C cardíaca humana (cTnC - Novo Castra ${ }^{\circledR}$ ) na diluição 1:40 (Pavarini et al.2012).

As Secções histológicas coradas em HE foram avaliadas em microscopia de luz e realizada a analise semi-quantitativa das lesões nas regiões cardíacas nos átrios, ventrículos e septo interventricular. Nas amostras histológicas cardíacas submetidas à imunohistoquímica, foram quantificadas as células não imunomarcadas em relação aos cardiomiócitos positivos para o anticorpo anti-troponina C (\%). 
Foi realizada a comparação das médias das contagens celulares foram comparadas entre si com o teste $\mathrm{T}$, realizada com o programa PrismGraph(c 6.01. O presente projeto de pesquisa foi aprovado pelo Comitê de Ética de Uso Animal (CEUA) da Universidade Federal do Recôncavo Baiano (UFRB), processo número 23007.013398/2012-21.

\section{RESULTADOS}

Os caprinos cronicamente intoxicados pela $P$. marcgravii apresentaram palidez difusa do miocárdio (Figura 1A), que se aprofundava no parênquima (Figura 1B), variando de discreta a acentuada. A avaliação histológica e imuno-histoquímica do miocárdio demonstrou alterações patológicas em todas as áreas investigadas (Quadro 1). A principal alteração histopatológica observada foi a tumefação e vacuolização perinuclear difusa de cardiomiócitos (Figura 2A), um pouco mais acentuada no ventrículo esquerdo, seguida pelo septo interventricular e ventrículo direito $(p>0,05)$. Nos átrios direito e esquerdo essas alterações foram menos intensas que nas demais áreas avaliadas $(\mathrm{p}<0,01)$.

Focos de inflamação linfohistiocítica discreta a leve (Figura 2B) foram observados em todas as áreas avaliadas $(p>0,05)$. As células inflamatórias encontravam-se adjacentes a raros cardiomiócitos isolados necróticos, com acentuada hipereosinofilia citoplasmática, cariopicnose e perda de estriações. Não foram observada áreas de fibrose nas secções histológicas das amostras cardíacas de todos os caprinos coradas pela técnica de Tricrômico de Masson.

O percentual de células não imunomarcadas pelo anticorpo anti-troponina $C$ cardíaca variou de 0,0 a 5,0\% nas regiões cardíacas analisadas $(p>0,05)$, representando os raros cardiomiócitos necróticos. Dessa forma, o padrão de imunomarcação foi difuso e intenso na maior parte das amostras, semelhante aos animais controle que tiveram $100 \%$ de imunomarcação pelo anticorpo. 
Nos três animais controle, não foram detectadas alterações anatomopatológicas dignas de nota em todos os fragmentos de tecidos analisados.

\section{DISCUSSÃO}

$\mathrm{Na}$ intoxicação experimental crônica de caprinos por $P$. marcgravii verificou-se distribuição difusa das lesões nas regiões cardíacas avaliadas. O padrão e distribuição dessas lesões, até o momento, não foram observados na intoxicação de ruminantes por plantas que contém MFA (Vasconcelos et al. 2008, Pavarini et al. 2011, Peixoto et al. 2012, Becker et al. 2013, Oliveira et al. 2013, Bandinelli et al. 2014, Lee et al. 2014). Ainda é desconhecida a razão para o desenvolvimento do padrão, distribuição e intensidade das lesões nos animais intoxicados. É possível que a exposição crônica à toxina da planta forneça condições subletais para o estabelecimento dessas alterações, muito distintas das observadas nas intoxicações agudas por P. marcgravii em ruminantes (Tokarnia et al. 1986, Tokarnia et al. 1991, Barbosa et al. 2003). Variações na taxa metabólica dos cardiomiócitos ou na permeabilidade das membranas à toxina nas diferentes regiões cardíacas, poderiam interferir na velocidade de ação, distribuição e efeito do MFA presente nas folhas das plantas (Buffa et al. 1977).

Dentre as alterações histopatológicas encontradas, a tumefação e vacuolização dos cardiomiócitos, com distribuição multifocal à difusa e em graus variáveis, foram as lesões preponderantes em $100 \%$ dos caprinos intoxicados. Essas alterações foram observadas anteriormente e de forma similar, apenas em caprinos cronicamente intoxicados por $P$. marcgravii no Distrito Federal (Reis jr et al. 2009).

A vacuolização de raras fibras cardíacas isoladas foi descrita em menos de $30 \%$ dos animais na intoxicação aguda experimental de caprinos pela planta (Tokarnia et al. 1991). Em ovinos experimentalmente intoxicados por monofluoracetato de sódio na África do Sul, foram encontradas lesões semelhantes no miocárdio, caracterizada pelo inchaço de fibras cardíacas e 
vacuolização na região perinuclear (Schultz et al. 1982). A intoxicação por MFA provoca marcado acúmulo de citrato nos tecidos, causado pelo bloqueio do ciclo de Krebs e da atividade respiratória e metabólica do órgão, principalmente no miocárdio e no sistema nervoso (ColichoZuanaze \& Satake 2005, Goncharov et al. 2005). A vacuolização acentuada dos cardiomiócitos em animais intoxicados por $P$. marcgravii reforça que o MFA contido na planta, possivelmente, causou a interrupção do ciclo de Krebs, depleção nos níveis de ATP teciduais e acúmulo de líquido intracelular.

$\mathrm{Na}$ avaliação das amostras na microscopia de luz, as alterações morfológicas nos cardiomiócitos dos caprinos sugerem edema celular. No entanto, na avaliação ultraestrutural o que se verificou foi a acentuada dilatação do retículo endoplasmático liso (Reis Jr. et al. 2009), diferentemente da lesão mitocondrial encontrada em células cardíacas em cultivo celular expostas ao monofluoracetato de sódio (Buffa et al. 1977). Essas diferenças talvez se expliquem devido à prolongada exposição das fibras miocárdicas à toxina nos caprinos intoxicados pela planta.

Necrose individual de fibras cardíacas nos animais cronicamente intoxicados pela $P$. marcgravii ocorreu de forma discreta e com distribuição semelhante à tumefação e vacuolização de cardiomiócitos. Essa lesão foi evidenciada pelo baixo percentual de células não imunomarcadas pelo anticorpo anti-troponina C cardíaca. A necrose discreta em escassas áreas focais de fibras cardíacas foi descrita anteriormente na intoxicação aguda pela planta em $50 \%$ dos caprinos (Tokarnia et al. 1991). Essa lesão pode ser observada em ruminantes intoxicados por plantas que contém MFA (Tokarnia et al. 1986, Pavarini et al. 2011, Peixoto et al. 2012, Oliveira et al. 2013), mas não é necessariamente sempre encontrada (Barbosa et al. 2003, Vasconcelos et al. 2008, Becker et al. 2013). 
O padrão de necrose e a imunomarcação dos cardiomiócitos pelo anticorpo antitroponina C cardíaca verificados nos caprinos, foram semelhantes ao reportado em bovinos e ovinos intoxicados por MFA (Santos et al. 2016). Porém essa alteração foi muito diferente da observada em bovinos naturalmente intoxicados por Amorimia exotropica, na qual há extensas áreas multifocais de necrose no miocárdio com ausência de marcação para cTnC nesses locais (Pavarini et al. 2012, Bandinelli et al. 2014). Apesar dessa planta causar morte súbita associada ao exercício em bovinos, espécimes de Amorimia sp. podem apresentar concentração de MFA de 50 a 100 vezes menor que na $P$. marcgravii (Lee et al. 2012) e necessitam ser ingeridas em grandes quantidades para causarem intoxicação (Pavarini et al. 2011, Soares et al. 2011). Essas diferenças de toxicidade entre plantas que contém MFA, certamente influenciaram na intensidade e extensão das alterações no miocárdio, especialmente na necrose de fibras miocárdicas. Ainda é importante considerar que pode haver diferenças na capacidade de metabolização do MFA entre as espécies de ruminantes (Eason et al. 1994, Gooneratne et al. 2008)

O processo inflamatório encontrado no coração dos caprinos cronicamente intoxicados pela planta pode ser observado esporadicamente na intoxicação aguda desses animais por $P$. marcgravii (Tokarnia et al. 1991), e também em ovinos (Tokarnia et al. 1986) e bovinos (Tokarnia \& Dobereiner 1986). A intoxicação experimental de ovinos por MFA resultou na presença de focos de células inflamatórias mononucleares semelhantes no miocárdio (Schultz et al. 1982, Gooneratne et al. 2008). A inflamação multifocal cardíaca de animais intoxicados por MFA ou plantas que contém essa substância, possivelmente, está relacionada com a necrose de fibras cardíacas. A exposição prolongada ao MFA na intoxicação crônica por $P$. marcgravii, pode permitir uma maior evolução do processo inflamatório frente a morte dos cardiomiócitos, tornando mais evidente sua visualização. 
A fibrose intersticial no miocárdio não foi observada nos animais do experimento, mas é encontrada esporadicamente em ovinos e caprinos intoxicados de forma aguda pela planta (Tokarnia et al. 1986, Tokarnia et al. 1991). O processo de fibroplasia nesses casos, provavelmente ocorre em virtude da necrose celular e substituição por tecido fibroso (Tokarnia et al. 1991). Bovinos e ovinos intoxicados naturalmente por outras plantas que contém MFA como Amorimia exotropica e Amorimia sepium, apresentaram severa fibrose intersticial cardíaca (Pavarini et al. 2011, Schons et al. 2011, Soares et al. 2011). Essa lesão também foi observada nas áreas de necrose e inflamação do miocárdio, em ovinos intoxicados de forma crônica ou subaguda pelo MFA (Schultz et al. 1982). A necrose discreta de cardiomiócitos nos caprinos cronicamente intoxicados por $P$. marcgravii poderia justificar a ausência de fibrose observada nesses animais.

Esse estudo demonstrou que a intoxicação crônica por P.marcgravii produz marcadas alterações no miocárdio de caprinos. As lesões degenerativas acentuadas e difusas nos cardiomiócitos se destacam por produzirem um padrão patológico único e ainda pouco conhecido em estudos de cardiotoxicidade. A morte súbita de ruminantes é uma das principais alterações observadas em rebanhos criados em áreas que contém plantas tóxicas que possuem MFA. Entretanto, alterações clínico-patológicas devido ao efeito cardiotóxico da exposição à baixas doses dessas plantas também devem ser investigadas, assim como a presença de outras plantas que contenham o monofluoracetato, como Amorímia pubiflora. 


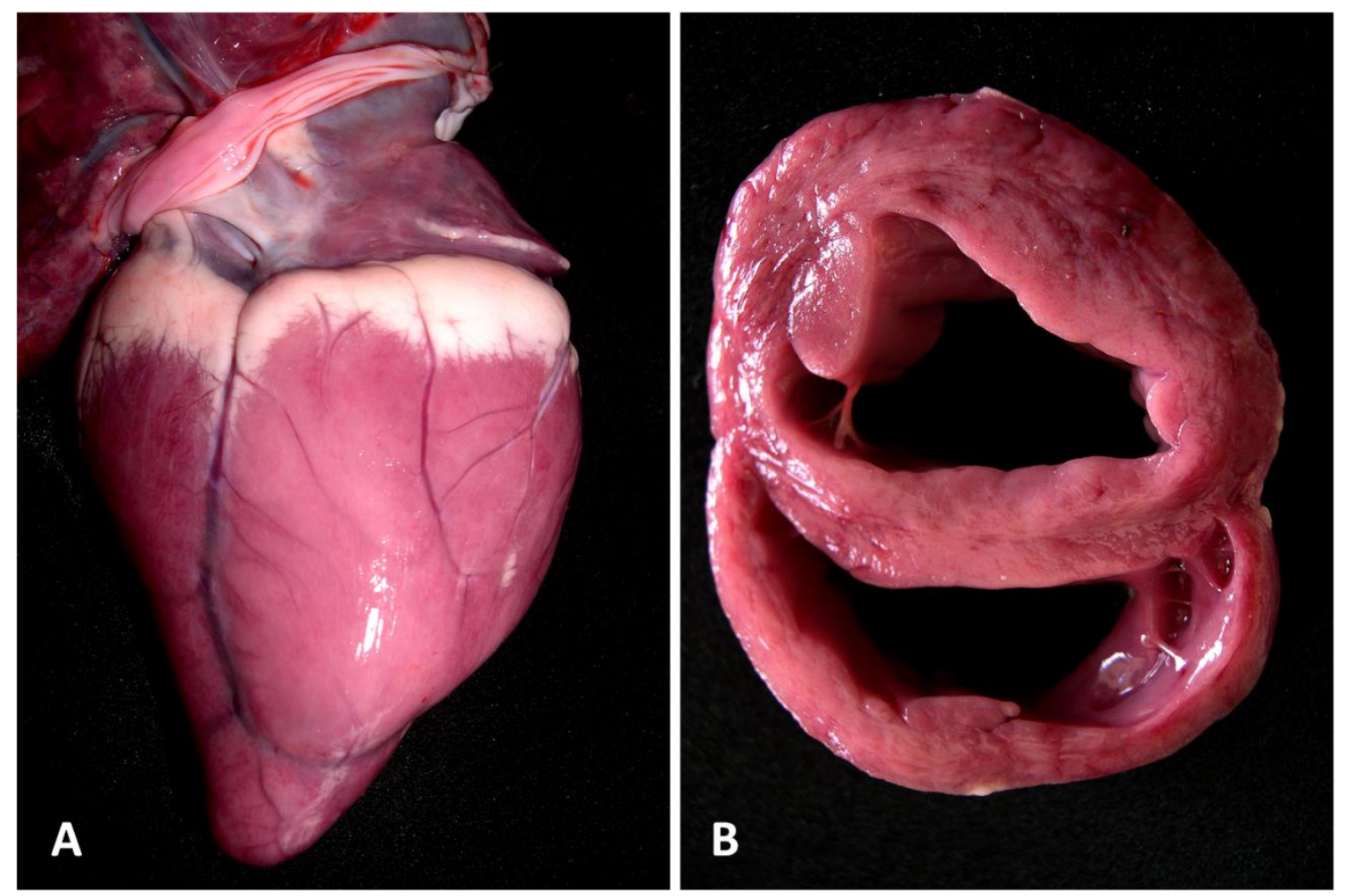

Figura 1. Caprino, coração. A. Palidez acentuada no ventrículo direito de animal cronicamente intoxicado por $P$. marcgravii. B. Corte transversal do coração do mesmo animal com palidez mural difusa nos ventrículos e septo interventricular.
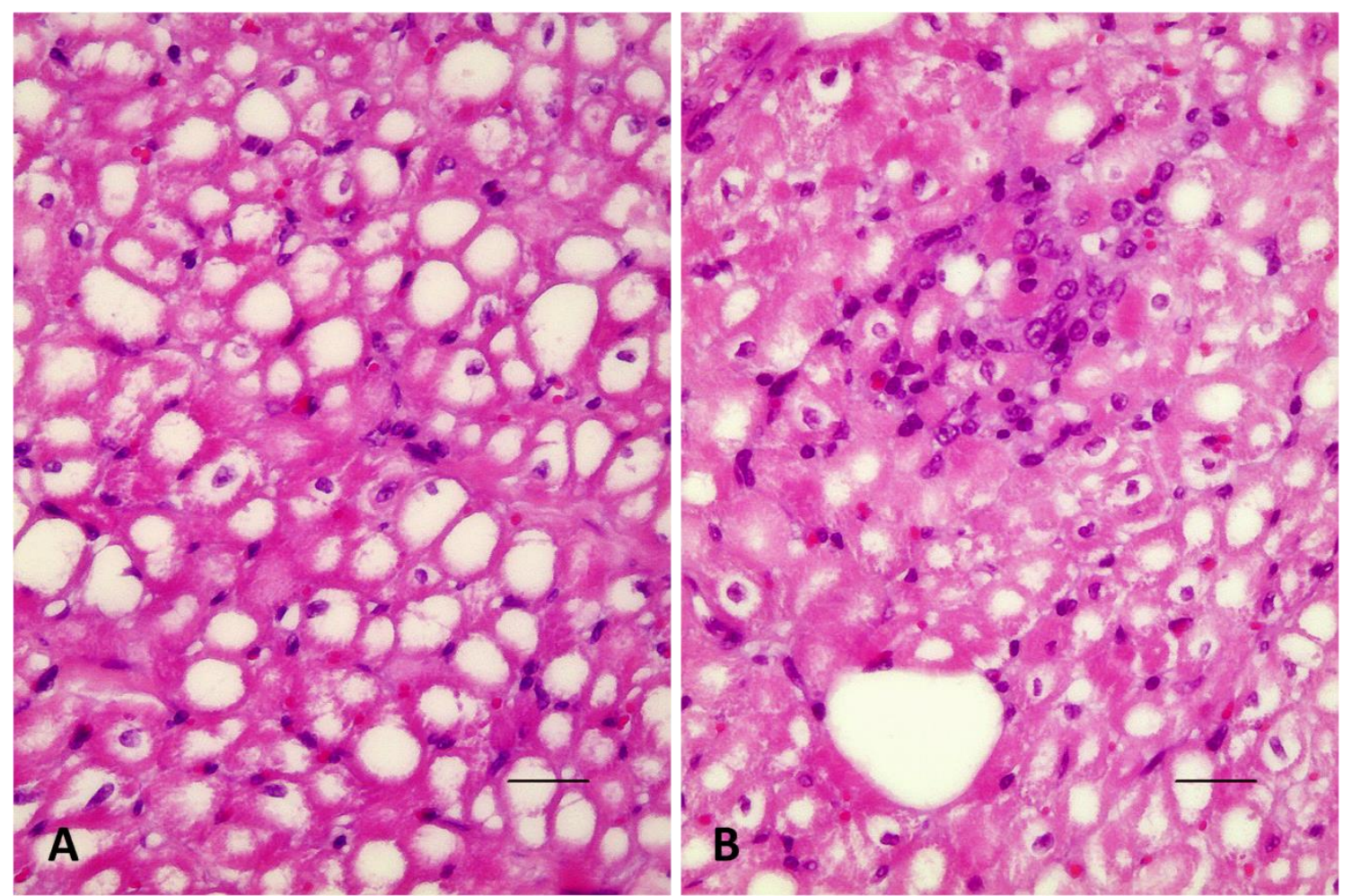

Figura 2. Caprino, coração. A. Vacuolização perinuclear difusa de cardiomiócitos. HE (barra $=50 \mu \mathrm{m}$ ). B. Infiltrado inflamatório linfo-histiocítico discreto focal por entre cardiomiócitos vacuolizados. HE (barra $=50 \mu \mathrm{m}$ ). 
Quadro 01. Alterações histopatológicas cardíacas em caprinos cronicamente intoxicados com P. marcgravii (Brasília, 2016).

\begin{tabular}{|c|c|c|c|c|c|c|c|c|c|c|c|c|c|c|c|}
\hline \multirow[t]{3}{*}{ Animal } & \multicolumn{15}{|c|}{ Regiões cardíacas } \\
\hline & \multicolumn{3}{|c|}{ VD } & \multicolumn{3}{|c|}{ VE } & \multicolumn{3}{|c|}{ SI } & \multicolumn{3}{|c|}{ AD } & \multicolumn{3}{|c|}{ AE } \\
\hline & TVC & ILH & NT\% & TVC & ILH & NT\% & TVC & ILH & NT\% & TVC & ILH & NT\% & TVC & ILH & NT\% \\
\hline PM 1 & + & $d$ & 3,60 & +++ & + & 1,33 & ++ & $d$ & 1,33 & + & - & 2,66 & ++ & + & 1,33 \\
\hline PM 2 & +++ & + & 3,00 & +++ & + & 4,00 & +++ & + & 1,00 & + & + & 5,00 & ++ & + & 3,60 \\
\hline PM 3 & +++ & + & 2,00 & +++ & + & 1,33 & +++ & + & 0,33 & + & $d$ & 1,50 & + & $d$ & 1,33 \\
\hline PM 4 & +++ & + & 1,00 & ++ & $d$ & 2,33 & ++ & + & 1,66 & + & $d$ & 0,66 & + & $d$ & 2,00 \\
\hline PM 5 & + & $d$ & 1,33 & +++ & + & 1,33 & +++ & + & 0,33 & - & + & 3,00 & + & $d$ & 3,66 \\
\hline PM 6* & + & + & 2,66 & +++ & + & 0,00 & +++ & + & 1,33 & + & - & 1,66 & + & - & 1,66 \\
\hline C1 & - & - & 0 & - & - & 0 & - & - & 0 & - & - & 0 & - & - & 0 \\
\hline C2 & - & - & 0 & - & - & 0 & - & - & 0 & - & - & 0 & - & - & 0 \\
\hline C3 & - & - & 0 & - & - & 0 & - & - & 0 & - & - & 0 & - & - & 0 \\
\hline
\end{tabular}

PM: animais intoxicados P. marcgravii; C: grupo controle; Região anatômica cardíaca: AD - átrio direito; AE - átrio esquerdo; SI - septo interventricular; VD - ventrículo direito; VE -

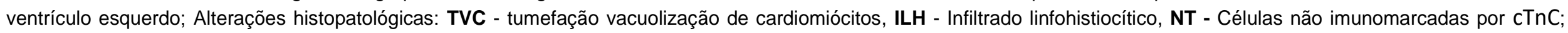
Intensidade da alteração: - sem alterações, $\mathbf{d}$ discreto, + leve, ++ moderada, +++ acentuada. * morte espontânea do animal com 28 dias. 


\section{REFERÊNCIAS}

Bandinelli M.B., Bassuino D.M., Fredo G., Mari C., Driemeier D., Sonne L. \& Pavarini S.P. 2014. Identificação e distribuição de lesões cardíacas em bovinos intoxicados por Amorimia exotropica. Pesq. Vet. Bras. 34(9):837-844

Barbosa E.F.G., Cardoso S.P., Cabral Filho S.L.S., Borges J.R.J., Lima E.M.M., Riet-Correa F. \& Castro M.B. 2015. Sinais clínicos e patologia da intoxicação crônica experimental de caprinos por Palicourea marcgravii. Pesq. Vet. Bras. 35(3):209-215.

Barbosa J. D., Oliveira C.M.C. \& Tokarnia H. C., 2003. Comparação da sensibilidade de bovinos e búfalos à intoxicação por Palicourea marcgravii ( Rubiaceae ) Pesq. Vet.Bras. 23(4): 167172.

Becker M., Caldeira F.H.B., Carneiro F.M., Oliveira L.P., Tokarnia C.H., Riet-Correa F., Lee, S.T \& Colodel, E.M. 2013. Importância da intoxicação por Amorimia publfora (Malpighiaceae) em bovino no Mato Grosso Sul: reprodução experimental da intoxicação em ovinos e bovinos. Pesq. Vet.Bras. 33(9): 1049-1056.

Buffa, P. Pasquali-Ronchetti I. Biochemical Lesions of Respiratory Enzymes and Configurational Changes of Mitochondrial in vivo. Cell Tissue Res., v.183, p. 1-23, 1977.

Collichio-Zuanaze R.C. \& Satake M. Aspectos clínicos e terapêuticos da intoxicação por fluoroacetato de sódio em animais domésticos: Revisão. Vet. Not. 11(2): 81-89, 2005

Conselho Federal de Medicina Veterinária. Guia Brasileiro de Boas Práticas em Eutanásia em Animais - Conceitos e Procedimentos Recomendados - Brasília, 2012 1v. (62p).

Cook D., Lee S. T., Taylorb C. M., Bassünerb B., Riet-Correa F., Pfistera J. A., Gardnera D.R. Detection of toxic monofluoroacetate in Palicourea species. Toxicon 80: 9-16.

Duarte A.L. L., Medeiros R.M.T., Carvalho F.K.L., Lee S. T., Cook D., Pfister J.A., Costa V.M.M., Riet-Corrêa F. 2014 Induction and transfer of resistance to poisoning by Amorimia (Mascagnia) septentrionalis in goats. J. Appl. Toxic.

Eason C.T., Gooneratne R., Fitzgerald H., Wright G., Frampton C. 1994. Persistence of sodium monofluoracetate in livestock animals and risk to humans. Hum. \& Experim. Toxicol.13:119122. 
Furlan F. H., Colodel E. M., Lemos R.A.A., Castro M. B., Mendonça F. S., \& Riet-Correa F. Poisonous plants affecting cattle in Central-Western Brazil. Intern. Journ. of Poison. Plant Research, 2: 1-13, 2012.

Goncharov, N. V., Jenkins, R.O., Radilov, A. S. Toxicology of fluoracetate: review, with possible directios for terapy research. 2006. Jor. Of Appl. Toxocol. 26: 148-161.

Gooneratne S.R., Eason C.T., Dickson C.J., Fitzgerald H., Wright G. 1995. Persistence os sodium monoflouracetate in rabbits and risk to non-target species. Human \& Experimental Toxicology. 14: 212-216.

Gooneratne S.R., Eason C.T., Milne L., Arthur D.G., Cook C. \& Wickstrom M. 2008. Acute and longterm effects of exposure to sodium monofluoracetate (1080) in sheep. Onderstepoort Journal of Veterinary Research, 75:127-139.

Lee S.T., Cook D., Riet-Correa F., Pfister J.A., Anderson W.R., Lima F.G. \& Gardner 8 D. 2012. Detection of monofluoracetate in Palicourea and Amorimia species. Toxicon 60:791-796.

Lee S.T., Cook D., Pfister J.A., Allen J.G., Colegate S.M., Riet-Correa F.and Taylor C.M. 2014. Monofluoracetate-containing Plants that are potentially toxic to livestock. Journal of Agricultural and Food Chemistry. 62:7345-7354.

Nogueira V.A., França T.N., Peixoto T. C., Caldas S.A., Armién A.G. \& Peixoto P.V. 2010. Intoxicação experimental por monofluoroacetato de sódio em bovinos: aspectos clínicos e patológicos. Pesq. Vet. Bras. 30(7):533-540.

Oliveira M.D., Riet-Correa, F. Carvalho, F.K., Silva G.B., Pereira W.S., Medeiros R.M.T. 2013. Indução de resistência a intoxicação por Palicourea aeneosfusca (Rubiaceae) mediante administração de doses sucessivas não tóxicas. Pesquisa Veterinária Brasileira. v.33(6)p.731734.

Pavarini S.P., Soares M.P., Bandarra P.M., Gomes D.C., Bandinelli M.B., Cruz C.E.F. \& Driemeier D. 2011. Sudden death in cattle due to the consumption of Amorimia exotropica (Malpighiaceae) in Rio Grande do Sul, Brazil. Mortes súbitas em bovinos causadas por Amorimia exotropica (Malpighiaceae) no Rio Grande do Sul. Pesq. Vet. Bras. 31(4):291296.

Pavarini S.P., Bandinelli M.B., Juffo G.D., Souza S.O., Driemeier D. \& Cruz C.E.F. 2012. Decreased expression of cardiac troponin C is associated with cardiac lesions in Amorimia exotropica poisoned cattle. Pesq. Vet.Bras. 32(10):1005- 1008. 
Peixoto T.C.; Nogueira V.A.; Caldas S.A.; França T.N.; Anjos B.L.; Aragão A.P.; Peixoto P.V. 2012. Efeito protetor da acetamida em bovinos indica monofluoracetato como princípio tóxico de Palicourea marcgravii (Rubiaceae). Pesq. Vet. Bras. V.32(4), p.319-328.

Riet-Correa F. \& Medeiros R.M.T. 2001. Intoxicações por plantas em ruminantes no Brasil e no Uruguai: importância econômica, controle e riscos para a saúde pública. Pesq. Vet.Bras. 21:38-42.

Pessoa C.R.M., Medeiros R.M.T., \& Riet-Correa F. 2013. Importância econômica, epidemiologia e controle das intoxicações por plantas no Brasil. Pesq. Vet. Bras. 33(6):752-758.

Reis Jr.J.L., Castro M.B., Moscardini A.C., Novais E.P.F., Borges J.R.J., Riet-Correa F., Howerth E. W. Histopatologic and ultrastructural findings of chronic experimental cardiotoxicity induced by monofluoracetate producing-plant Palicourea marcgravii. AAAVLD Annual Conference Proceedings 52 ed. 2009. p.169.

Santos A.M., Peixoto P.V., D’Ávila M.S., Peixoto T.C., França T.N., Costa S.Z.R., Cid G.C. \& Nogueira V.A. 2016. Troponina C na detecção imuno-histoquímica de alterações regressivas precoces no miocárdio de bovinos e ovinos intoxicados por monofluoroacetato de sódio. Pesq. Vet. Bras. 36(2):67-72.

Schons S.V., Lopes T.V., Melo T.L., Lima J.P., Riet-Correa F., Barros M.A.B., Schild A.L.P. 2012. Intoxicações por plantas em ruminantes e equídeos na região central de Rondônia. Ciência Rural. 42( 7): 12571263.

Soares M.P., Pavarini S.P.,Adrien M.L., Quevedo P.S., Schild A.L., Peixoto P.V., Cruz C.E.F. \& Driemeier D. 2011. Amorimia exotropica poisoning as a presumptive cause of myocardial fibrosis in cattle. J.VET.Diagn. Invest. 23: 1226. DOI:10.1177 1040638711425586.

Shultz R. A., Coetzer W. Kellerman Y.S., Naudé T.W. Observations on the clinical, cardiac and histopatological effects in sheep. 1982. Onderstepoort Jornal of Veterinay Research, 49: 237-245.

Tokarnia C. H.; Döbereiner J.; Couceiro J.E.M. \& Silva A.C.C. 1983. Intoxicação por Palicourea aeneofusca (Rubiaceae) a causa de " mortes súbitas em bovinos na Zona da Mata de Pernambuco. Pesq. Vet. Bras. 3(3): 75-79.

Tokarnia C.H., Peixoto P.V. \& Döbereiner J. Intoxicação experimental por Palicourea marcgravii (Rubiaceae) em ovinos. 1986. Pesq. Vet. Bras. 6: 121-131. 
Tokarnia C.H. \& Döbereiner J. Intoxicação por Palicourea marcagravii em bovinos no Brasil. 1986. Pesq. Vet. Bras. 6: 73-92

Tokarnia C.H., Peixoto P.V. \& Döbereiner J. Plantas que afetam o funcionamento do coração de bovinos no Brasil. 1990. Pesq. Vet.Bras. 10: 1-10,

Tokarnia, C.H., Peixoto P.V., Döbereiner J. Intoxicação experimental por Palicourea marcgravii (Rubiaceae) em caprinos. 1991. 11: 65-70.

Tokarnia C.H., Döbereiner J. \& Peixoto P.V. Poisonous plants affecting livestock in Brazil. Toxicon 40 (2002) 1635-1660.

Tokarnia C.H., Brito, M.F., Barbosa, J.D. Peixoto P.V. \& Döbereiner J. 2012. Plantas que afetam o funcionamento do coração. Plantas Tóxicas do Brasil. 1. ed. Rio de Janeiro: Helianthus,. p.556

Vasconcelos J.S., Riet-Correa F., Dantas A.F., Medeiros R.M.T. \& Dantas A.J.A. 2008. 34 Mortes súbitas em bovinos causadas por Palicourea aeneofusca (Rubiaceae) e Mascagnia rigida (Malpighiaceae) na Zona da Mata Paraibana. Pesq. Vet. Bras. 28: 457-460.

Vickery B, Vickery M.L. Fluoride metabolism in Dichapetalum toxicarium. Phytochemitry. 1972, 11:1905-1909. 


\title{
Capítulo 2
}

\section{Avaliação clínico-patológica da intoxicação crônica experimental pela Palicourea marcgravii e Palicourea aeneofusca em ovinos no Distrito federal.}

\author{
Edson de F. G. Barbosa e Márcio B. Castro
}

\begin{abstract}
Barbosa E.F.G. \& Castro M.B. 2016. [Clinical and pathological evaluation of chronicle experimental poisoning of sheep by Palicourea marcgravii and Palicourea aeneofusca] Pesquisa Veterinária Brasileira 00(0):00. Laboratório de Patologia Veterinária, Hospital Veterinário, Universidade de Brasília, Via L4 Norte, Cx. Postal 4508, Brasília, DF 70910-970, Brazil. E-mail: mbcastro@unb.br
\end{abstract}

Palicourea marcgravii and Palicourea aeneofusca are among the principal toxic plants of cattle interest in Brazil because they cause the acute death of ruminants. Due to the high toxicity of these plants, there is evidence that chronic ingestion of small doses is capable of producing cardiotoxicity and death of the animals. The present study evaluated the toxic effect of up to 30 days of dry leaves of $P$. marcgravii and $P$. aenefusca on sheep at a dose of $0.05 \mathrm{~g} / \mathrm{kg}$ body weight. The main clinical alterations in the animals intoxicated by the plants were anorexia, apathy, tachycardia, tachypnea, muscle tremors, reluctance to walk and positive jugular pulse. These animals presented areas of pallor, congestion and hemorrhage in the myocardium with various foci of cardiomyocyte necrosis. In the kidneys and nervous system, degenerative-necrotic changes were detected in the tubular and neuronal epithelium, respectively. The changes observed in chronically intoxicated animals by Palicourea marcgravii and Palicourea aenefusca demonstrate a clinico-pathological picture distinct from the acute form of intoxication, which should be considered in the diagnosis of ruminant diseases created extensively.

INDEX TERMS: monofluoracetate, ovine, cardiotoxicity, poisoning, toxic plants

RESUMO- A Palicourea marcgravii e a Palicourea aeneofusca estão entre as principais plantas tóxicas de interesse pecuário no Brasil por causarem a morte aguda de ruminantes. Devido a elevada toxicidade dessas plantas, existem evidências que a ingestão crônica de pequenas doses seja capaz de produzir cardiotoxicidade e morte dos animais. O presente estudo avaliou o efeito tóxico da administração por até 30 dias de folhas secas de $P$. marcgravii e de $P$. aeneofusca para ovinos na dose de $0,05 \mathrm{~g} / \mathrm{kg}$ de peso vivo. As principais alterações clínicas nos animais intoxicados pelas plantas foram anorexia, apatia, taquicardia, taquipnéia, tremores musculares, relutância em andar e pulso jugular positivo. Esses animais apresentaram áreas de palidez, congestão e hemorragia no miocárdio com vários focos de necrose de cardiomiócitos. Nos rins e sistema nervoso, foram detectadas alterações degenerativo-necróticas no epitélio tubular e neuronal respectivamente. As alterações observadas em animais intoxicados cronicamente por Palicourea marcgravii e a Palicourea aeneofusca demonstram quadro clínico-patológico distinto da forma aguda da intoxicação, que deve ser considerado no diagnóstico das enfermidades de ruminantes criados extensivamente.

TERMOS DE INDEXAÇÃO: monofluoacetato, ovino, cardiotoxicidade, intoxicação, plantas tóxicas 


\section{INTRODUÇÃO}

Atualmente no Brasil, a ingestão de plantas tóxicas pelos animais de interesse pecuário causa severas perdas econômicas à pecuária nacional e quando associadas a raiva e o botulismo, são as principais causas de morte de bovinos no País. As plantas causadoras de morte súbita são consideradas responsáveis pela metade das perdas por plantas de ruminantes no Brasil (Pessoa et al. 2013). Nesse contexto, se destaca a Palicourea marcgravii, distribuída amplamente no território nacional, nas principais áreas de pecuária brasileiras (Tokarnia et al. 2002). A Palicourea aeneofusca ocorre na zona da mata e agreste dos estados da Paraíba, Pernambuco e Bahia, causando perdas consideráveis à pecuária nordestina (Vasconcelos et al. 2008, Tokarnia et al. 2012). Essas duas plantas apresentam grande potencial de intoxicação aos ruminantes criados extensivamente, devido a sua elevada palatabilidade e grandes quantidades do monofluoracetato (MFA) em suas folhas (Krebs et al. 1994, Lee et al. 2012, Cook et al. 2014).

Apesar da reconhecida importância como causa de morte súbita e perdas de grande monta para a pecuária brasileira, há suspeitas que a ingestão crônica de $P$. marcgravii ou Palicourea aeneofusca também possa intoxicar e causar a morte de animais a campo. A distribuição dessas plantas nas diversas regiões pecuárias do País ocorre de maneira bastante variável, podendo ser encontrada adensada em algumas localidades e muito esparsa em outras. Esta situação permite que os animais possam ingerir pequenas quantidades da planta em determinadas condições, levando a um quadro clínico-patológico bastante diverso do tradicional visto nas intoxicações agudas (Tokarnia et al. 1983, Tokarnia \& Döbereiner, 1986; Tokarnia et al., 1986, Tokarnia et al.1990, Tokarnia et al., 1991, Tokarnia et al. 2002, Tokarnia et al 2012). O fato foi comprovado na intoxicação crônica de caprinos que ingeriram subdoses de P. marcgravii, causando severa cardiotoxicidade e morte dos animais (Barbosa et al 2015).

Uma vez que a intoxicação crônica por plantas que causam morte súbita e contém MFA é ainda pouco conhecida, torna-se importante que isso também seja investigado em ovinos e bovinos, visando a caracterização e identificação das alterações clínico e patológicas nessas espécies. O presente estudo foi realizado com objetivo de avaliar se a administração de subdoses letais diárias de folhas dessecadas de Palicourea marcgravii e Palicourea aeneofusca para ovinos é capaz de produzir o quadro de intoxicação nessa espécie. Dessa forma, verificar se ocorrem possíveis variações nas formas clínico-patológicas, visando prevenir a ocorrência 
de intoxicação à campo, por meio do diagnóstico precoce e acurado evitando assim perdas econômicas.

\section{MATERIAL E MÉTODOS}

O experimento foi realizado entre o mês de julho até início de setembro de 2016, no Centro de Manejo de Ovinos (CMO), da Fazenda Águas Limpas FAL-UnB, 1556'S e 47으' 'W, a $1080 \mathrm{~m}$ de altitude, Brasília, DF. As amostras de $P$. marcgravii foram coletadas em matas na Cidade Ocidental - GO, no entorno do Distrito Federal. As plantas da P. aeneofusca foram colhidas na região da zona da mata baiana em Oliveira dos Campinho - BA. As plantas utilizadas no experimento eram procedentes de propriedades onde havia histórico de morte súbita de bovinos associada ao exercício. Após coletadas, as folhas foram separadas e dessecadas à sombra, quando atingiram $40 \%$ do peso verde, conservadas em sacos plásticos vedados, com proteção contra a luz.

Foram utilizados 15 ovinos, sem raça definida, machos e fêmeas, com idade variando de 8 a 12 meses de idade, clinicamente sadios, divididos randomicamente em 3 grupos de 5 animais cada. Os ovinos dos grupos $P$. marcgravii (PM) e $P$. aeneofusca (PA) receberam a dose individual por via oral diária de $0,05 \mathrm{~g} / \mathrm{Kg} /$ peso vivo (PV) de folhas dessecadas das plantas por até 30 dias. $O$ grupo controle $(\mathrm{GC})$ recebeu volumoso e concentrado. Cada um dos grupos de animais foi mantido em baias fechadas cimentadas e receberam silagem de milho a vontade e 1\% PV/animal/dia de concentrado comercial para ovinos sem adição de qualquer ionóforos em sua fórmula.

A avaliação clínica diária matinal de todos os animais foi realizada durante as 4 semanas do experimento. Amostras de sangue, para obtenção de soro sanguíneo, colhidas duas vezes por semana para avaliação dos níveis de AST, CK e CKMB em analisador automático (Cobas C111 - Roche C). Elevações dos níveis séricos enzimáticos foram consideradas quando atingiram valores superiores ao valor máximo de referência da população (VMRP), estimados a partir dos níveis séricos médios de todos os animais utilizados no experimento, antes do início do período experimental, somado a duas vezes o desvio padrão (Stockham \& Scott 2008). 
Os ovinos que receberam as plantas até o final do período experimental e um animal do grupo controle, foram submetidos a eutanásia com barbitúrico intravenoso de ação ultracurta, segundo os procedimentos recomendados para ruminantes (CFMV, 2012). Todos os ovinos que morreram intoxicados ou foram submetidos a eutanásia e necropsia logo em seguida, colhidos fragmentos de órgãos (coração, pulmões, fígado, rins, adrenal, baço, sistema nervoso central, intestinos, pâncreas, linfonodos e músculo estriado esquelético) e fixados em solução de formol tamponado a $10 \%$. As amostras foram rotineiramente processadas, incluídas em parafina, realizados cortes histológicos de $4 \mu \mathrm{m}$ de espessura e corados pela técnica hematoxilina-eosina $(\mathrm{HE})$ para avaliação em microscopia de luz. As lesões microscópicas nos órgãos e tecidos foram avaliadas quanto a sua distribuição e realizada a analise semi-quantitativa das alterações no miocárdio.

As médias das atividades séricas enzimáticas foram analisadas com o método ANOVA e comparadas pelo teste de Tukey. A comparação das frequências das lesões histológicas e de sua intensidade entre os grupos e regiões cardíacas analisadas, foi feita pelo teste exato de Fisher e teste T respectivamente, com o programa PrismGraph ( 6.01. O presente trabalho foi aprovado pelo Comitê de Ética de Uso Animal (CEUA) da Universidade Federal do Recôncavo da Bahia (UFRB), processo número 23007.013398/2012-21.

\section{RESULTADOS}

A intoxicação crônica de ovinos por Palicourea marcgravii e Palicourea aeneofusca produziu sinais clínicos severos e a morte de $80 \%$ e de $60 \%$ dos animais respectivamente no período estudado. Os dois grupos de ovinos intoxicados apresentaram níveis séricos médios de CK maiores que o grupo controle $(p<0,05)$. A maioria dos animais que recebeu $P$. marcgravii e $P$. aeneofusca demonstrou elevações séricas semanais de CK (Figura 1A e 1B) e morreram intoxicados, exceto o animal PA4. Esse ovino, e aqueles que não tiveram elevações de CK maiores que o VMRP (PM2 e PA3), foram submetidos a eutanásia ao final do experimento. As mensurações de CKMB e AST no soro dos animais intoxicados e controle não apresentaram variações significativas durante todo o experimento $(p>0,05)$.

As principais alterações clínicas observadas foram anorexia, apatia, taquicardia, taquipneia, pulso jugular positivo, tremores musculares, relutância em andar e decúbito 
esternal (Quadro 1). Episódios de convulsões tônico clônicas e síncope foram observados nos animais PA1, PA3 e PA5.

Os sinais clínicos surgiram entre o 14 e e o 29 일 dias do experimento, com evolução de 1 a 10 dias, mesmo sem estimular os animais ao exercício. As alterações clínicas se intensificaram gradativamente com a evolução da intoxicação, até a morte dos animais ou eutanásia. Não houve diferenças significativas entre a mortalidade, tempo de surgimento dos sinais clínicos, evolução clínica e frequência dos sinais clínicos entre os grupos de animais intoxicados $(p>0,05)$. O grupo controle não apresentou alterações em seu estado clínico durante o experimento.

O principal achado macroscópico observado em todos os ovinos cronicamente intoxicados, foi a palidez leve a severa, focalmente extensa a difusa do miocárdio, circundadas por áreas de congestão e hemorragia difusa (Figura 2) e/ou petequial. Os animais PM3, PM5 e PA5 evidenciaram hidropericárdio leve a moderado. Nos rins de todos animais intoxicados havia moderada a acentuada palidez difusa do córtex (Figura 3) e aumento de volume no fígado, com palidez e evidenciação discreta do padrão lobular. Com exceção dos animais eutanasiados, todos os demais apresentaram congestão e edema pulmonar discreto a moderado.

O coração foi o órgão que apresentou alterações microscópicas mais intensas, frequentes e significativas nos ovinos intoxicados (Quadro 2), seguido dos rins e fígado. O aumento da eosinofilia e cariopicnose multifocal, leve a acentuada, sugerindo a necrose de cardiomiócitos (Figura 4A), foi a principal lesão verificada no miocárdio dos ovinos intoxicados. Em animais que receberam $P$. marcgravii, essas alterações foram observadas com maior intensidade no septo interventricular que nas demais áreas avaliadas, e nos ventrículos quando comparado aos átrios.

Ovinos intoxicados por $P$. aeneofusca apresentaram focos de hipereosinofilia e cariopicnose de cardiomiócitos mais severos no septo interventricular do que no ventrículo direito e nos átrios $(p<0,05)$, não havendo diferenças entre as outras regiões avaliadas $(p>0,05)$. Essas lesões foram mais intensas no septo interventricular e no ventrículo direito de ovinos que receberam $P$. marcgravii comparadas ao grupo intoxicado por $P$. aeneofusca $(p<0,05)$. 
A vacuolização citoplasmática na região perinuclear multifocal, escassa a leve de cardiomiócitos (Figura 4B) foi outra lesão relevante nos grupos de ovinos intoxicados. Ao redor das áreas de hipereosinofilia e cariopicnose de fibras cardíacas havia infiltrado inflamatório discreto a leve constituído por linfócitos e histiócitos.

Nos rins de todos os animais que receberam as plantas, havia degeneração multifocal leve a moderada das células epiteliais tubulares, caracterizada por marcada vacuolização, com áreas focais de cariopicnose (Figura 5A). No fígado dos animais intoxicados, os hepatócitos apresentavam tumefação centro-lobular leve, com citoplasma de aspecto ligeiramente dissociado e vacuolizado.

No sistema nervoso central (SNC) dos animais PM2 e PA3 foram visualizados escassos neurônios isolados com marcada hipereosinofilia e angulação citoplasmáticas, e retração celular (Figura 5B), alguns deles com cariopicnose e cariorexia, distribuídos de forma aleatória no corpo striatum. Não foram observadas alterações histológicas dignas de nota nos demais órgãos e tecidos avaliados de todos animais do experimento e no grupo controle.

\section{DISCUSSÃO}

A administração de subdoses diárias de $0,05 \mathrm{~g} / \mathrm{kg}$ de folhas secas de Palicourea marcgravii e Palicourea aeneosfusca por até 30 dias consecutivos, produziu a intoxicação e a morte da maioria dos animais. Pela primeira vez foi demonstrado o efeito da toxicidade crônica por essas plantas em ovinos.

A dose utilizada no presente estudo foi semelhante à utilizada na intoxicação crônica experimental pela P. marcgravii em caprinos (Barbosa et al. 2015). O fornecimento de 0,05g/kg/PV de folhas dessecadas correspondeu aproximadamente a $10 \%$ da dose tóxica aguda mínima de P.marcgravii para ovinos (Tokarnia et al. 1986). Até o momento, não há experimentos de toxicidade com $P$. aeneofusca na espécie, no entanto, foi necessária um pouco maior de folhas frescas da planta (a partir de $0,65 \mathrm{~g} / \mathrm{kg} / \mathrm{PV}$ ) para causar a intoxicação aguda em caprinos (Passos 1983) e de 0,75g/kg/PV para bovinos (Tokarnia et al. 1983). Independente das variações que possam ocorrer nos níveis de MFA nas plantas utilizadas nesse estudo, e que também podem ter sido influenciadas pela dessecação das folhas, a dose utilizada foi insuficiente para causar a forma aguda da intoxicação, permitindo a administração prolongada das plantas. 
Nos ovinos cronicamente intoxicados por $P$. marcgravii e $P$. aeneofusca houve grande aumento dos níveis séricos de CK, principalmente próximo à morte dos animais. Nas intoxicações experimentais aguda e crônica por MFA em ovinos, ocorreram aumentos séricos apenas de AST (Goonoratne et al. 2008). A elevação de CK nos ovinos possivelmente refletiu a ação cardiotóxica do MFA contido nas folhas das plantas utilizadas, resultado da lesão em cardiomiócitos. CKMB e AST séricos não foram eficazes para detectar essas alterações nos ovinos.

Os principais sinais clínicos observados foram semelhantes entre os animais cronicamente intoxicados, independentemente da planta administrada, porém, a mortalidade foi maior em ovinos que receberam $P$. marcgravii. As alterações clínicas nesses animais foram equivalentes aquelas descritas na intoxicação aguda de ovinos por $P$. marcgravii (Tokarnia et al. 1986), e em ruminantes pela mesma planta e por P. aeneofusca (Passos 1983, Tokarnia et al. 1983, Vasconcelos et al. 2008, Oliveira et al. 2013). A maior mortalidade no grupo que ingeriu P. marcgravii possivelmente seja explicada pelo maior teor de MFA na $P$. marcgravii em comparação a P. aeneofusca (Lee et al. 2012).

O tempo para o surgimento dos sinais clínicos foi comparável ao descrito na intoxicação crônica de caprinos por P. marcgravii (Barbosa et al. 2015). Entretanto, é importante destacar que as alterações clínicas se manifestaram espontaneamente mesmo sem estímulo ao exercício. Na forma crônica experimental da intoxicação em ovinos, as alterações clínicas permaneceram por vários dias, em contraste com a forma aguda por plantas que contêm MFA, onde precedem a morte, geralmente exacerbadas quando o animal é estimulado a se movimentar (Tokarnia et al. 1983, Tokarnia et al. 1986, Tokarnia et al. 1990, Tokarnia et al.1991, Vasconcelos et al. 2008, Pavarini et al. 2011, Becker et al. 2013). Até o momento, não há explicação conhecida para justificar essas alterações, mas a exposição crônica a pequenas doses da toxina presente nas plantas, possivelmente forneceu condições adversas de toxicidade para que ocorressem.

A similaridade das alterações clínicas em ambos os grupos de ovinos cronicamente intoxicados por $P$. marcgravii e por $P$. aeneofusca, com a forma aguda da intoxicação, reforça o efeito acumulativo da ingestão de doses subletais das plantas. Ao considerar os dias de experimento, a ingestão de folhas secas das plantas foi de 0,75 a 1,5 g/kg/PV. Esses valores são muito próximos aos utilizados nas intoxicações agudas de ovinos (Tokarnia et al. 1986) e 
outros ruminantes por P. marcgravii (Tokarnia et al. 1990, Tokarnia et al. 1991, Barbosa et al. 2003, Soto-Blanco et al. 2004) e por P. aeneofusca (Tokarnia et al. 1983, Vasconcelos et al. 2008, Tokarnia et al. 2012, Oliveira et al. 2013). O fracionamento da dose tóxica tem comprovado o efeito acumulativo de ambas as plantas em ruminantes (Tokarnia et al. 1983, Tokarnia et al. 1986, Tokarnia et al. 1990, Tokarnia et al. 1991, Tokarnia et al. 2002, Oliveira et al. 2013). Na intoxicação experimental com monofluoacetato de sódio em ovinos esse efeito foi observado com sinais clínicos semelhantes aqueles verificados em ruminantes naturalmente intoxicados por plantas que contêm o MFA (Schutz et al. 1982).

A dose utilizada na exposição crônica de ovinos às plantas foi comparativamente menor que em caprinos cronicamente intoxicados por $P$. marcgravii, sugerindo que ovinos são mais susceptíveis à intoxicação, enquanto caprinos suportaram doses maiores e mais prolongadas de $P$. marcgravii (Barbosa et al 2015). Essa variação na toxidade das plantas entre ovinos e caprinos poderia ser explicada pela capacidade aproximadamente duas vezes maior nessa espécie de metabolização e excreção de monofluoracetato em comparação aos ovinos (Eason et al. 1994).

Três animais do grupo PA apresentaram episódios de convulsões tônico-clônicas e síncope durante o experimento, o que não ocorreu no grupo PM. Esses sinais clínicos foram semelhantes na intoxicação experimental crônica por MFA em ovinos (Shultz et al. 1982, Goonoratne et al. 2008). Porém, diferiram dos observados nos estágios finais da intoxicação aguda por plantas que contêm MFA, caracterizados por tremores musculares, decúbito, movimentos de pedalagem e morte (Passos 1983, Tokarnia et al. 1990, Tokarnia et al. 1991, Barbosa et al. 2003, Soto-Blanco et al. 2004, Vasconcelos et al. 2008, Peixoto et al. 2012, Tokarnia et al. 2012, Oliveira et al 2013).

A principal alteração macroscópica verificada em todos os animais do experimento foi a marcada palidez multifocal do miocárdio circundadas por áreas de hemorragia e congestão, variando em intensidade de moderada a acentuada. Estas alterações são semelhantes aquelas observadas em caprinos cronicamente intoxicados por $P$. marcgravii, porém hemorragia e congestão não estavam presentes (Barbosa et al. 2015). A intoxicação crônica de ovinos pelas plantas difere da intoxicação aguda por P. marcgravii e P. aeneosfusca (Passos 1983, Tokarnia et al. 1983, Tokarnia et al. 1990, Tokarnia et al. 1991, Barbosa et al. 2003, Soto-Blanco et al. 2004, Vasconcelos et al. 2008, Peixoto et al. 2012, Tokarnia et al. 2012, Oliveira et al 2013) e 
por MFA (Shultz et al. 1982, Eason et al. 1994, Goonoratne et al. 2008, Nogueira et al. 2010, Peixoto et al. 2012) onde não há alterações macroscópicas cardíacas ou em outros órgãos.

A necrose de cardiomiócitos foi mais intensa em ovinos que em caprinos cronicamente intoxicados por $P$. marcgravii, onde a vacuolização de dessas células foi a alteração mais marcante (Barbosa et al. 2015). A tumefação e vacuolização de fibras do miocárdio foram discreta nos ovinos intoxicados pelas plantas. O predomínio da necrose em cardiomiócitos em ovinos cronicamente intoxicados, em comparação a marcante degeneração de fibras miocárdicas em caprinos, sugere diferenças na capacidade de detoxificação do MFA entre as duas espécies. O padrão de lesão cardíaca identificado em animais cronicamente intoxicados pelas plantas é similar ao observado na exposição crônica de ovinos ao MFA (Shultz et al. 1982).

Outro achado importante, foi a maior intensidade da necrose de cardiomiócitos no septo interventricular e ventrículo direito de ovinos intoxicados por $P$. marcgravii que por $P$. aeneofusca. Em caprinos cronicamente intoxicados por P. marcgravii, a distribuição das lesões nas regiões cardíacas foi semelhante, entretanto predominou a degeneração acentuada de fibras cardíacas (Barbosa et al. 2015). As diferenças no efeito cardiotóxico das plantas entre ovinos e caprinos reforçam a maior capacidade de eliminar o MFA dessa espécie (Eason et al. 1994). A interpretação desses achados demonstra que a intoxicação crônica por $P$. marcgravii e por $P$. aeneofusca em ovinos produz principalmente necrose multifocal de cardiomiócitos, detectada pela elevação sérica de CK.

No entanto, a enzima CKMB utilizada no presente estudo, mesmo mais específica na detecção precoce de lesões cardíacas que a CK, a mesma não apresentou nenhuma elevação, durante a realização de todo protocolo experimental. Talvez por que o kit utilizado seja específico para espécie humana, e ainda não há um próprio para espécie ovina.

A palidez difusa e degeneração hidrópico-vacuolar do epitélio tubular foram alterações patológicas presentes no rim de todos os ovinos que receberam ambas as plantas. Esse padrão de lesão foi previamente observado em caprinos cronicamente intoxicados por $P$. marcgravii (Barbosa et al. 2015), porém ocorreu de forma menos intensa nos ovinos. Diferentemente da forma crônica da intoxicação em pequenos ruminantes, a maioria das espécies de animais intoxicados na forma aguda pela P.marcgravii e pela $P$. aeneofusca apresentou a degeneração do revestimento tubular renal apenas focal e isolada, ou muitas vezes ausente (Tokarnia et al. 
1990, Tokarnia et al. 1991, Barbosa et al. 2003, Oliveira et al. 2013). Essa alteração também foi reproduzida em bovinos intoxicados experimentalmente por MFA (Nogueira et al 2010, Peixoto et al. 2012), mas não ocorreu em ovinos (Shultz et al. 1982, Goonoratne et al 2008).

As alterações hepáticas e pulmonares observadas nos ovinos cronicamente intoxicados pela $P$. marcgravii e $P$. aeneofusca, possivelmente estão relacionadas diretamente às lesões degenerativas e necróticas em diferentes graus, verificadas no miocárdio destes animais. Este fato pôde ser demonstrado pela congestão venosa (clinicamente verificada como estase e pulso jugular positivo evidente) e degeneração vacuolar na região centrolobular hepática (com evidenciação no padrão lobular), possivelmente resultantes de falha na função cardíaca. Caprinos intoxicados de maneira semelhante por $P$. marcgravii apresentaram esse mesmo padrão de lesão nesses órgãos (Barbosa et al. 2015).

Dentre as lesões patológicas nos ovinos cronicamente intoxicados, se destaca a degeneração neuronal isquêmica principalmente no corpo striatum, nos animais que receberam o maior número de doses das plantas e foram submetidos a eutanásia ao final do experimento. É importante ressaltar que essa alteração foi observada tanto em animal que teve alterações neurológicas severas quanto em ovino que não apresentou nenhum sinal clínico associado ao SNC. A necrose e degeneração neuronal nessas áreas foi descrita na forma crônica da intoxicação por MFA em ovinos (Goonoratne et al. 2008). Entretanto, essas alterações, até o momento, não foram observadas na intoxicação natural ou experimental de ruminantes por plantas que contém MFA (Tokarnia et al. 1983, Tokarnia et al. 1986, Tokarnia et al. 1990, Tokarnia et al. 1991, Tokarnia et al. 2002, Barbosa et al. 2003, Soto-Blanco et al. 2004, Vasconcelos et al. 2008, Pavarini et al. 2011, Peixoto et al. 2012, Tokarnia et al. 2012, Becker et al. 2013, Oliveira et al. 2013). Na intoxicação crônica de caprinos por P. marcgravii, também não ocorreram alterações morfológicas neuronais (Barbosa et al 2015).

Além do efeito direto do MFA nas células neuronais dos ovinos, a toxina poderia inibir secundariamente a recaptação de neurotransmissores pelas células da glia, causando a elevação dos níveis extracelulares de glutamato, produzindo lesões por exocitotoxicidade neuronal (Nicoleti et al. 1996, Hassel et al. 1997). As estruturas que compõem o corpo striatum são consideradas particularmente suscetíveis a injuria devido à privação de aporte energético e pela exocitotoxicidade pelo glutamato (Olney 1990). 
As alterações patológicas cardíacas, renais e no sistema nervoso central (SNC) dos ovinos cronicamente intoxicados, certamente ocorreram devido ao efeito tóxico à exposição prolongada ao MFA contido nas folhas de $P$. marcgravii e de $P$. aeneofusca. A forma crônica da intoxicação produziu severo efeito cardiotóxico e favoreceu o desenvolvimento de alterações morfológicas marcantes cardíacas, renais e até mesmo neuronais que praticamente são desconhecidas na intoxicação aguda por Palicourea spp. em ruminantes (Tokarnia et al. 1983, Tokarnia et al. 1986, Tokarnia et al. 1990, Tokarnia et al. 1991, Barbosa et al. 2003, Soto-Blanco et al. 2004, Vasconcelos et al. 2008, Peixoto et al. 2012, Tokarnia et al. 2012).

Plantas que contêm MFA, ou essa substância isoladamente, provocam marcado acúmulo de citrato nos tecidos, devido ao bloqueio do ciclo de Krebs, com redução da atividade respiratória e energética principalmente no miocárdio e no sistema nervoso (Goncharov et al. 2005, Lee et al. 2014). Na intoxicação experimental de ovinos e coelhos por MFA, o princípio tóxico pode ser encontrado em maiores quantidades nos rins, coração, músculo esquelético e fígado respectivamente (Eason et al. 1994, Goonoratne et al 1995). Dessa forma, pode-se supor que em ovinos cronicamente intoxicados pelas plantas, os órgãos e tecidos mais afetados são aqueles onde há maior acúmulo de MFA, favorecendo o surgimento de lesões devido à toxicidade.

As alterações clínico-patológicas em ovinos submetidos à exposição crônica à $P$. marcgravii e $P$. aeneofusca demonstraram características únicas, com lesões morfológicas marcantes no coração, rins, fígado e SNC dos animais intoxicados. Essa forma de intoxicação deve ser considerada no diagnóstico diferencial das causas de morte em ruminantes, em regiões de pecuária extensiva e de ocorrência dessas plantas. Ainda são necessárias novas investigações para determinar os mecanismos envolvidos na patogênese da intoxicação crônica por plantas que contém MFA, para elucidar a formação do padrão marcante e quase exclusivo de lesões teciduais. 


\section{CONCLUSÕES}

Palicourea marcgravii e a Palicourea aeneofusca são tóxicas, e mesmo expostos a subdoses, podem intoxicar-se e morrer. Ovinos intoxicados cronicamente por essas plantas apresentaram alterações clínico-patológicas marcantes, resultantes de lesões severas no miocárdio, rins e SNC. Apesar da intoxicação crônica natural por plantas que contém MFA ser praticamente desconhecida em todo o mundo, o potencial para causar a morte de animais deve ser considerado em surtos de mortalidade em ruminantes a pasto. 


\section{REFERÊNCIAS}

Barbosa E.F.G., Cardoso S.P., Cabral Filho S.L.S., Borges J.R.J., Lima E.M.M., Riet-Correa F. \& Castro M.B. 2015. Sinais clínicos e patologia da intoxicação crônica experimental de caprinos por Palicourea marcgravii. Pesq. Vet. Bras. 35(3):209-215.

Barbosa J. D., Oliveira C.M.C. \& Tokarnia H. C., 2003. Comparação da sensibilidade de bovinos e búfalos à intoxicação por Palicourea marcgravii ( Rubiaceae ) Pesq. Vet. Bras. 23(4): 167172.

Becker M., Caldeira F.H.B., Carneiro F.M., Oliveira L.P., Tokarnia C.H., Riet-Correa F., Lee, S.T \& Colodel, E.M. 2013. Importância da intoxicação por Amorimia publfora (Malpighiaceae) em bovino no Mato Grosso Sul: reprodução experimental da intoxicação em ovinos e bovinos. Pesq. Vet. Bras. 33(9): 1049-1056.

Buffa, P. Pasquali-Ronchetti I. Biochemical Lesions of Respiratory Enzymes and Configurational Changes of Mitochondrial in vivo. Cell Tissue Res., v.183, p. 1-23, 1977.

Cook D., Lee S. T., Taylorb C. M., Bassünerb B., Riet-Correa F., Pfistera J. A., Gardnera D.R. Detection of toxic monofluoroacetate in Palicourea species. Toxicon 80: 9-16.

Collichio-Zuanaze R.C. \& Satake M. Aspectos clínicos e terapêuticos da intoxicação por fluoroacetato de sódio em animais domésticos: Revisão. 2005. Vet. Not. 11(2): 81-89.

Conselho Federal de Medicina Veterinária. Guia Brasileiro de Boas Práticas em Eutanásia em Animais - Conceitos e Procedimentos Recomendados - Brasília, 2012 1v. (62p).

Eason C.T., Gooneratne R., Fitzgerald H., Wright G., Frampton C. 1994. Persistence of sodium monofluoracetate in livestock animals and risk to humans. Hum. \& Experim. Toxicol.13:119122.

Furlan F. H., Colodel E. M., Lemos R.A.A., Castro M. B., Mendonça F. S., \& Riet-Correa F. 2012.Poisonous plants affecting cattle in Central-Western Brazil. Intern. Journ. of Poison. Plant Research, 2: 1-13.

Goncharov, N. V., Jenkins, R.O., Radilov, A. S. Toxicology of fluoracetate: review, with possible directios for terapy research. 2006. Jor. Of Appl. Toxocol. 26: 148-161.

Gooneratne S.R., Eason C.T., Dickson C.J., Fitzgerald H., Wright G. 1995. Persistence of sodium monoflouracetate in rabbits and risk to non-target species. Human \& Experimental Toxicology. 14: 212-216. 
Gooneratne S.R., Eason C.T., Milne L., Arthur D.G., Cook C., Wickstrom. Acute and long-term effects of exposure of monofluoracetate (1080) in sheep. Onderstepoort Jornal of Veterinary Research, 75: 127, 2008.

Hassel B., Bachelard H., Jones P., Fonnurn F., Sonnewald U. Trafficking of Amino Acids Between Neurons and Glia In Vivo. Effects of Inhibition of Glial Metabolism by Fluoroacetate. Journal of Cerebral Blood Flow and Metabolism 17:1230-1238.

Krebs H.C., Kemmerling W. \& Habermehl G. 1994. Qualitative and quantitative determination of fluoroacetic acid in Arrabidea bilabiata and Palicourea marcgravii by F-NMR spectroscopy. Toxicon 32: 909-913.

Lee S.T., Cook D., Riet-Correa F., Pfister J.A., Anderson W.R., Lima F.G. \& Gardner 8 D. 2012. Detection of monofluoracetate in Palicourea and Amorimia species. Toxicon 60:791-796.

Lee S.T., Cook D., Pfister J.A., Allen J.G., Colegate S.M., Riet-Correa F. \& Taylor C.M. 2014. Monofluoracetate-containing Plants that are potentially toxic to livestock. Journal of Agricultural and Food Chemistry. 62:7345-7354.

Nicoletti F., V. Bruno, Copani A., Casabona G., Knöpfel T. Metabotropic glutamate receptors: a new target for the therapy of neurodegenerative disorders. Trends Neurosci. (1996) 19, 267271.

Nogueira V.A., França T.N., Peixoto T. C., Caldas S.A., Armién A.G. \& Peixoto P.V. 2010. Intoxicação experimental por monofluoroacetato de sódio em bovinos: aspectos clínicos e patológicos. Pesq. Vet. Bras. 30(7):533-540.

Oliveira M.D., Riet-Correa, F. Carvalho, F.K., Silva G.B., Pereira W.S., Medeiros R.M.T. 2013. Indução de resistência a intoxicação por Palicourea aeneosfusca (Rubiaceae) mediante administração de doses sucessivas não tóxicas. Pesq. Vet. Bras. 33(6):731-734.

Olney J. W. Excitotoxin-mediated neuron death in youth and old age. Progress in Brain Research, Vol. 86.

Passos D.A. 1983. Intoxicação experimental em caprinos (Capra hircus) por Palicourea aeneofusca (M.Arg.) Standl. (Rubiaceae). Dissertação de Mestrado, Univ. Fed. Rural de Pernambuco, Recife, PE. 40p.

Pavarini S.P., Soares M.P., Bandarra P.M., Gomes D.C., Bandinelli M.B., Cruz C.E.F. \& Driemeier D. 2011. Sudden death in cattle due to the consumption of Amorimia exotropica (Malpighiaceae) in Rio Grande do Sul, Brazil. Mortes súbitas em bovinos causadas por 
Amorimia exotropica (Malpighiaceae) no Rio Grande do Sul. Pesq. Vet. Bras. 31(4):291296.

Peixoto T.C., Nogueira V.A., Caldas S.A., França T.N., Anjos B.L., Aragão A.P. \& Peixoto P.V. 2012. Efeito protetor da acetamida em bovinos indica monofluoracetato como princípio tóxico de Palicourea marcgravii (Rubiaceae). Pesq. Vet. Bras. V.32(4), p.319-328.

Riet-Correa F. \& Medeiros R.M.T. 2001. Intoxicações por plantas em ruminantes no Brasil e no Uruguai: importância econômica, controle e riscos para a saúde pública. Pesq. Vet. Bras. 21:38-42.

Pessoa C.R.M., Medeiros R.M.T., \& Riet-Correa F. 2013. Importância econômica, epidemiologia e controle das intoxicações por plantas no Brasil. Pesq. Vet. Bras. 33(6):752-758.

Reis Jr.J.L., Castro M.B., Moscardini A.C., Novais E.P.F., Borges J.R.J., Riet-Correa F., Howerth E. W. Histopatologic and ultrastructural findings of chronic experimental cardiotoxicity induced by monofluoracetate producing-plant Palicourea marcgravii. AAAVLD Annual Conference Proceedings 52 ed. 2009. p.169.

Schons S.V., Lopes T.V., Melo T.L., Lima J.P., Riet-Correa F., Barros M.A.B., Schild A.L.P. Intoxicações por plantas em ruminantes e equídeos na região central de Rondônia. 2012. Ciência Rural. 42(7): 1257-1263.

Soares M.P., Pavarini S.P.,Adrien M.L., Quevedo P.S., Schild A.L., Peixoto P.V., Cruz C.E.F., Driemeier D. Amorimia exotropica poisoning as a presumptive cause of myocardial fibrosis in cattle. J.VET.Diagn. Invest. 2011 23: 1226. DOI:10.1177 1040638711425586.

Soto-Blanco B., Haraguchi M., Silva J.A., Gorniak L. S. Intoxicação natural de caprinos e ovinos por P. marcgravii (Rubiaceae). Revista Caatinga. 2004; 17(1):52-56.

Soares M.P., Pavarini S.P.,Adrien M.L., Quevedo P.S., Schild A.L., Peixoto P.V., Cruz C.E.F. \& Driemeier D. 2011. Amorimia exotropica poisoning as a presumptive cause of myocardial fibrosis in cattle. J.VET.Diagn. Invest. 23: 1226. DOI:10.1177 1040638711425586.

Shultz R. A., Coetzer W. Kellerman Y.S., Naudé T.W. Observations on the clinical, cardiac and histopatological effects in sheep. 1982. Onderstepoort Jornal of Veterinay Research, 49: 237-245.

Stockham, S.L., Scott, M.A. Fundamental of Veterinary Clinical Pathology. 2nd ed. Blackwell Publishing, lowa, p.16-17. 2008. 
Tokarnia C. H.; Döbereiner J.; Couceiro J.E.M. \& Silva A.C.C. 1983. Intoxicação por Palicourea aeneofusca (Rubiaceae) a causa de " mortes súbitas em bovinos na Zona da Mata de Pernambuco. Pesq. Vet. Bras. 3(3): 75-79.

Tokarnia C.H., Peixoto P.V. \& Döbereiner J. Intoxicação experimental por Palicourea marcgravii (Rubiaceae) em ovinos. 1986. Pesq. Vet. Bras. 6: 121-131.

Tokarnia C.H. \& Döbereiner J. Intoxicação por Palicourea marcagravii em bovinos no Brasil. 1986. Pesq. Vet. Bras. 6: 73-92.

Tokarnia C.H., Peixoto P.V. \& Döbereiner J. Plantas que afetam o funcionamento do coração de bovinos no Brasil. 1990. Pesq. Vet.Bras. 10: 1-10,

Tokarnia, C.H., Peixoto P.V., Döbereiner J. Intoxicação experimental por Palicourea marcgravii (Rubiaceae) em caprinos. 1991. 11: 65-70.

Tokarnia C.H., Döbereiner J. \& Peixoto P.V. Poisonous plants affecting livestock in Brazil. Toxicon 40 (2002) 1635-1660.

Tokarnia C.H., Brito, M.F., Barbosa, J.D. Peixoto P.V. \& Döbereiner J. 2012. Plantas que afetam o funcionamento do coração. Plantas Tóxicas do Brasil. 1. ed. Rio de Janeiro: Helianthus,. p.556

Vasconcelos J.S., Riet-Correa F., Dantas A.F., Medeiros R.M.T. \& Dantas A.J.A. 2008. 34 Mortes súbitas em bovinos causadas por Palicourea aeneofusca (Rubiaceae) e Mascagnia rigida (Malpighiaceae) na Zona da Mata Paraibana. Pesq. Vet. Bras. 28: 457-460.

Vickery B, Vickery M.L. Fluoride metabolism in Dichapetalum toxicarium. Phytochemitry. 1972, 11:1905-1909. 


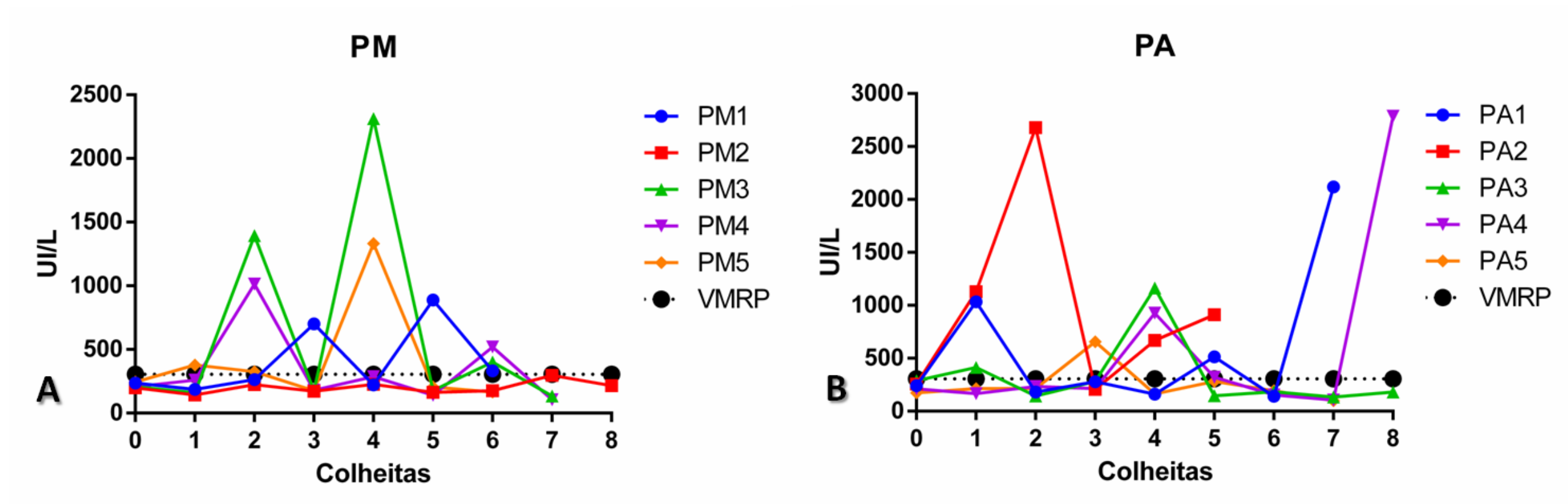

Figura 1. A - Níveis séricos individuais de CK em ovinos cronicamente intoxicados por $P$. marcgravii (PM). B - Níveis séricos individuais de CK em ovinos cronicamente intoxicados por e $P$. aeneofusca (PA). 
Quadro 1. Intoxicação crônica experimental de ovinos pela P. marcgravii e P.aeneofusca e sinais clínicos (Brasília, 2016).

\begin{tabular}{|c|c|c|c|c|c|c|c|c|c|c|c|c|}
\hline \multirow[t]{2}{*}{ Animal } & \multirow[t]{2}{*}{ Sexo } & \multirow[t]{2}{*}{ TDIP } & \multirow{2}{*}{$\begin{array}{c}\text { ISC } \\
\text { (dia) }\end{array}$} & \multirow{2}{*}{$\begin{array}{c}\text { CCL } \\
\text { (dias) }\end{array}$} & \multicolumn{7}{|c|}{ Sinais clínicos } & \multirow[t]{2}{*}{ Desfecho } \\
\hline & & & & & ANX & APT & TCP & PJP & TRM & RAD & DEC & \\
\hline PM 1 & $M$ & 21 & $19^{\circ}$ & 2 & + & + & + & + & + & + & + & $M$ \\
\hline PM 2 & $M$ & 30 & $20^{\circ}$ & 10 & - & - & + & + & + & + & - & $E$ \\
\hline PM 3 & $F$ & 29 & $19^{\circ}$ & 10 & + & - & + & + & + & + & + & $M$ \\
\hline PM 4 & $M$ & 26 & $23^{\circ}$ & 3 & - & - & + & + & + & + & - & $M$ \\
\hline PM 5 & $\mathrm{~F}$ & 22 & $20^{\circ}$ & 2 & - & + & + & + & + & + & + & $\mathrm{M}$ \\
\hline PA 1 & $\mathrm{M}$ & 29 & $20^{\circ}$ & 9 & + & + & + & + & + & + & + & $M$ \\
\hline PA 2 & $\mathrm{~F}$ & 15 & $14^{\circ}$ & 1 & + & + & + & + & + & + & + & $M$ \\
\hline PA 3 & $M$ & 30 & $29^{\circ}$ & 1 & - & - & + & + & - & - & - & $\mathrm{E}$ \\
\hline PA 4 & $\mathrm{~F}$ & 30 & $23^{\circ}$ & 7 & - & + & + & - & + & + & + & $E$ \\
\hline PA 5 & $M$ & 30 & $21^{\circ}$ & 9 & + & + & + & + & + & + & + & $M$ \\
\hline GC 1 & $M$ & - & - & - & - & - & - & - & - & - & - & $E$ \\
\hline GC 2 & $\mathrm{~F}$ & - & - & - & - & - & - & - & - & - & - & - \\
\hline GC 3 & $M$ & - & - & - & - & - & - & - & - & - & - & - \\
\hline GC 4 & $\mathrm{~F}$ & - & - & - & - & - & - & - & - & - & - & - \\
\hline GC 5 & $M$ & - & - & - & - & - & - & - & - & - & - & - \\
\hline
\end{tabular}

Sexo: M - macho, F - fêmea. TDIP - total de dias de ingestão da planta; ISC - início dos sinais clínicos; CCL - curso clínico. Sinais clínicos: ANX anorexia; APT - apatia; TCP - taquicardia e taquipneia; PJP - Pulso jugular positivo; TRM - tremores musculares; RAD - relutância em andar; DEC - decúbito esternal. Desfecho: M - morte, E - eutanásia. Interpretação: + presente, - ausente. 
Quadro 2. Alterações histopatológicas cardíacas em ovinos cronicamente intoxicados por $P$. marcgravii e a $P$. aeneofusca.

\begin{tabular}{|c|c|c|c|c|c|c|c|c|c|c|c|c|c|c|c|}
\hline \multirow[t]{2}{*}{ Animal } & \multicolumn{3}{|c|}{ VD } & \multicolumn{3}{|c|}{ VE } & \multicolumn{3}{|c|}{ SI } & \multicolumn{3}{|c|}{ AD } & \multicolumn{3}{|c|}{$\mathrm{AE}$} \\
\hline & $\mathrm{HCC}$ & TVC & ILH & HCC & TVC & ILH & HCC & TVC & ILH & $\mathrm{HCC}$ & TVC & ILH & $\mathrm{HCC}$ & TVC & ILH \\
\hline PM 1 & ++ & - & $r$ & ++ & - & + & +++ & $r$ & + & + & - & $r$ & + & - & + \\
\hline PM 2 & + & + & + & + & + & + & ++ & ++ & + & + & - & $r$ & + & - & $r$ \\
\hline PM 3 & ++ & + & + & + & - & - & ++ & $r$ & + & + & - & $r$ & + & - & $r$ \\
\hline PM 4 & + & - & + & ++ & - & + & +++ & + & + & + & - & $r$ & + & - & + \\
\hline PM 5 & ++ & - & + & ++ & - & + & ++ & $r$ & + & + & - & $r$ & + & - & + \\
\hline PA 1 & + & - & + & + & - & + & + & - & + & + & - & $r$ & + & - & $r$ \\
\hline PA 2 & + & - & + & ++ & - & + & ++ & $r$ & + & + & - & - & + & - & $r$ \\
\hline PA 3 & + & ++ & $r$ & + & ++ & + & + & ++ & ++ & + & + & $r$ & + & + & + \\
\hline PA 4 & + & + & + & + & + & ++ & ++ & + & + & + & $r$ & + & + & - & $r$ \\
\hline PA 5 & + & + & $r$ & + & + & + & ++ & + & + & + & $r$ & + & + & - & $r$ \\
\hline GC 1 & - & - & - & - & - & - & - & - & - & - & - & - & - & - & - \\
\hline
\end{tabular}

PM - ovinos intoxicados por P. marcgravii, PA - ovinos intoxicados por P. aeneofusca, GC - grupo controle. Região anatômica cadíacas: VD - ventrículo direito, VE - ventrículo esquerdo, SI - septo interventricular, AD - átrio direito, AE - átrio esquerdo. Alterações histopatológicas: HCC - hipereosinofilia e cariopicnose de cardiomiócitos, TVC tumefação e vacuolização de cardiomiócitos, ILH - Infiltrado inflamatório linfo-histiocítico. Intensidade: - sem alterações, $\mathbf{r}$ - raros, + discreta, ++ moderada, +++ acentuada. 


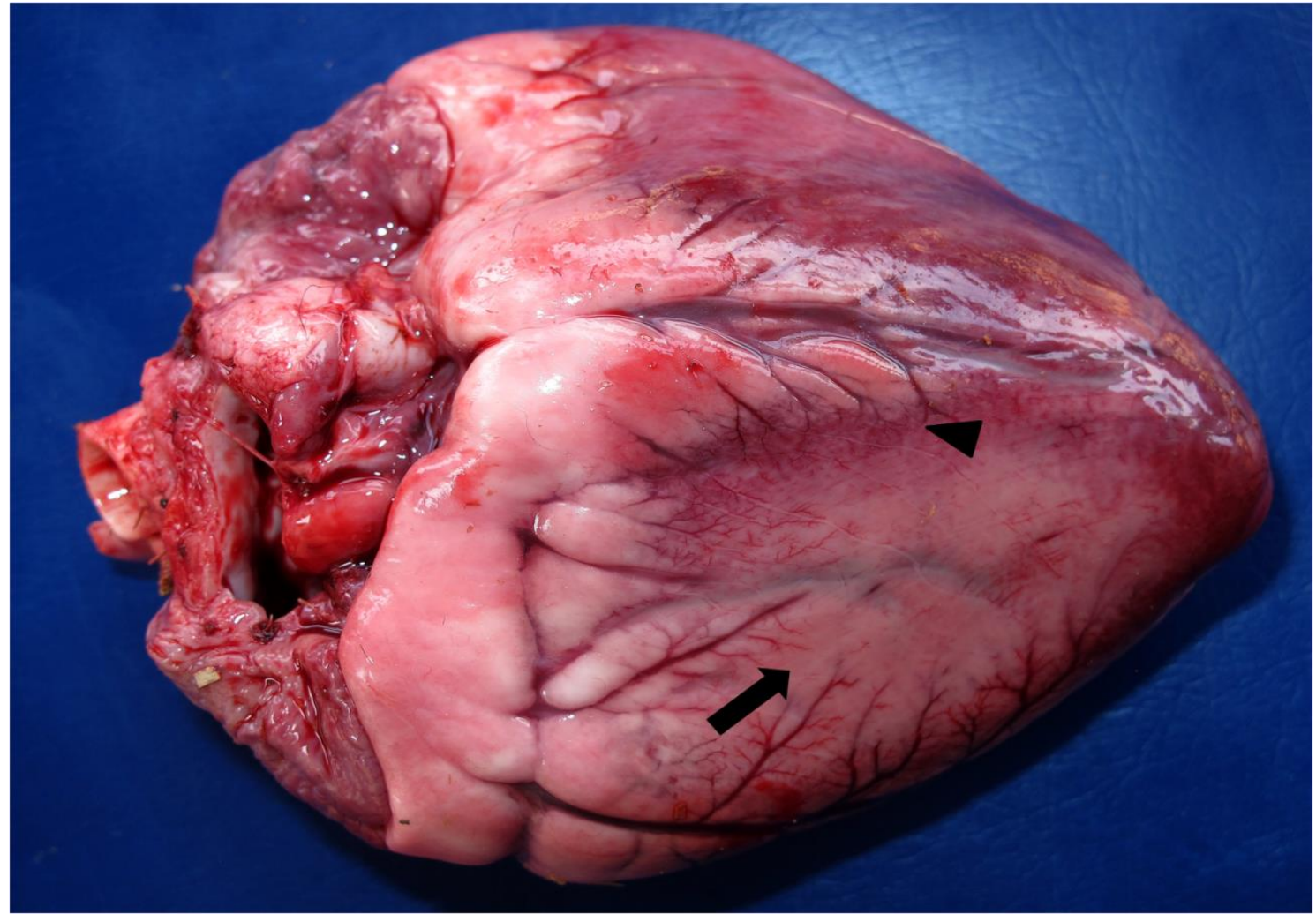

Figura 2. Ovino, coração. Intoxicação crônica por $P$. marcgravii. Palidez acentuada do miocárdio (seta) circundada por áreas de hemorragia e congestão (cabeça de seta)

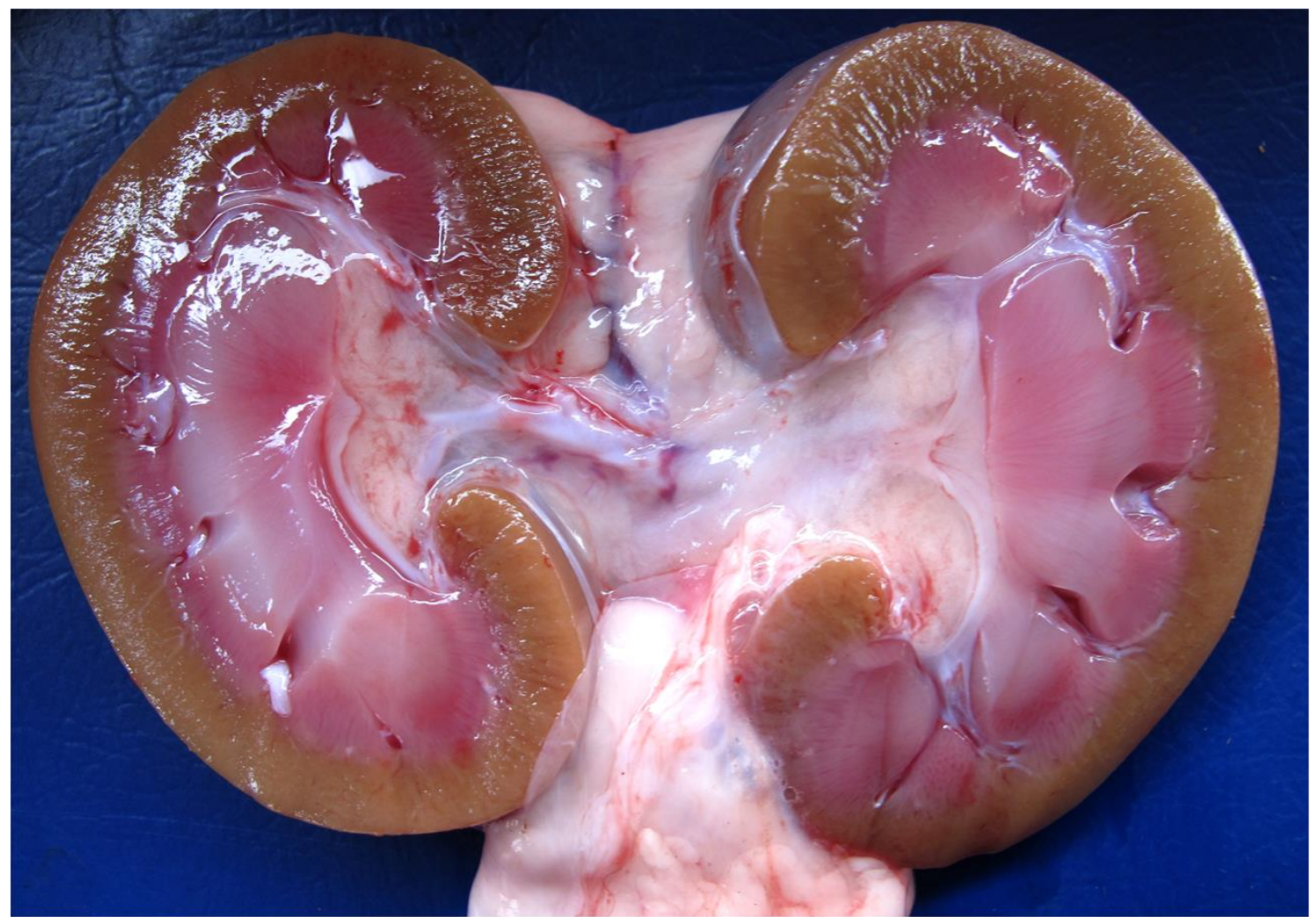

Figura 3. Ovino, rim. Intoxicação crônica por P. aeneofusca. Palidez difusa no córtex renal. 

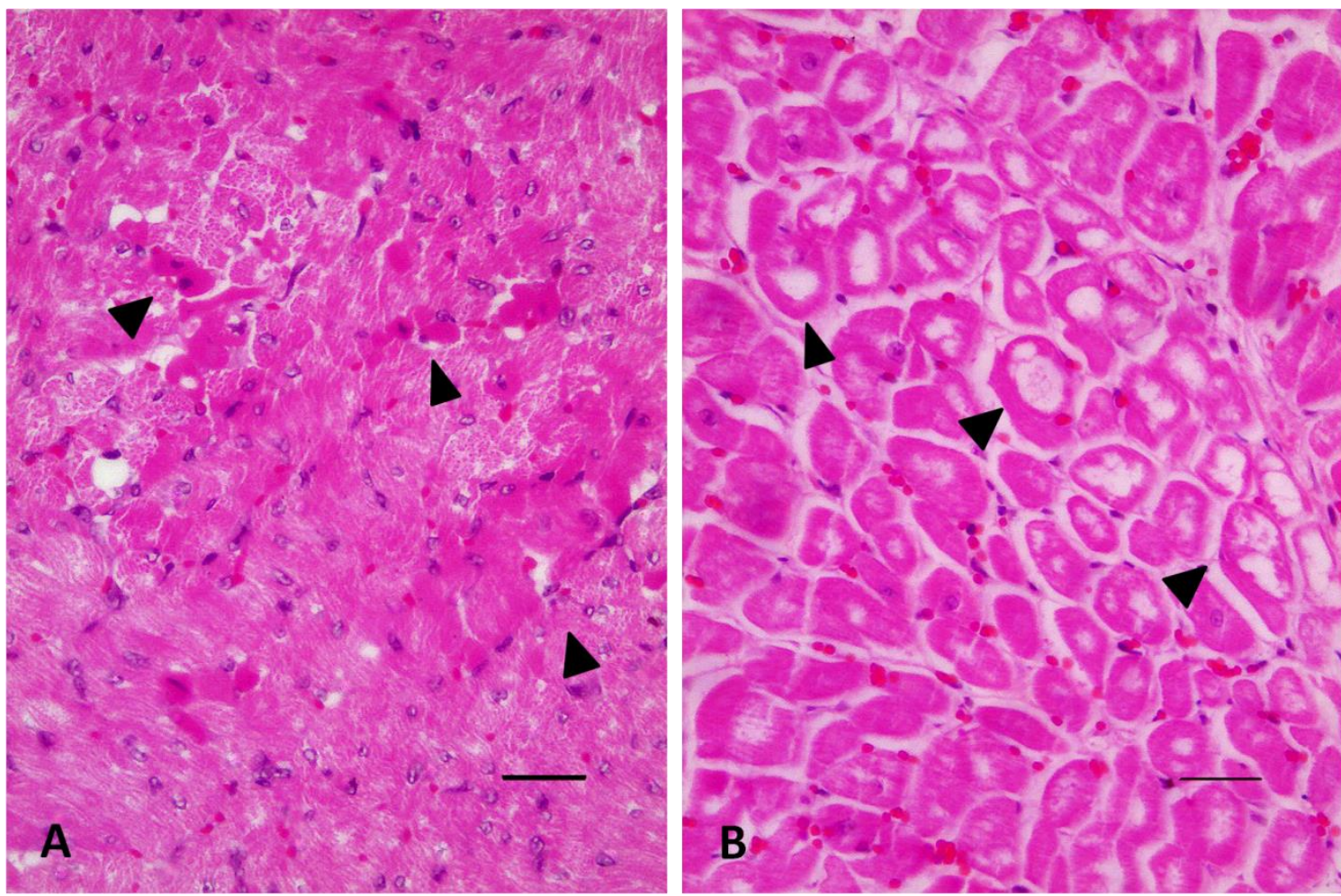

Figura 4. A - Ovino, coração, septo interventricular. Intoxicação crônica por P. marcgravii. Áreas multifocais de hipereosinofilia e cariopicnose (cabeça de seta) em cardiomiócitos. HE (barra= $50 \mu \mathrm{m})$. B - Ovino, coração, ventrículo direito. Intoxicação crônica por $P$. aeneofusca. Tumefação e vacuolização (cabeça de seta) focal de cardiomiócitos. HE (barra= $50 \mu \mathrm{m}$ ).
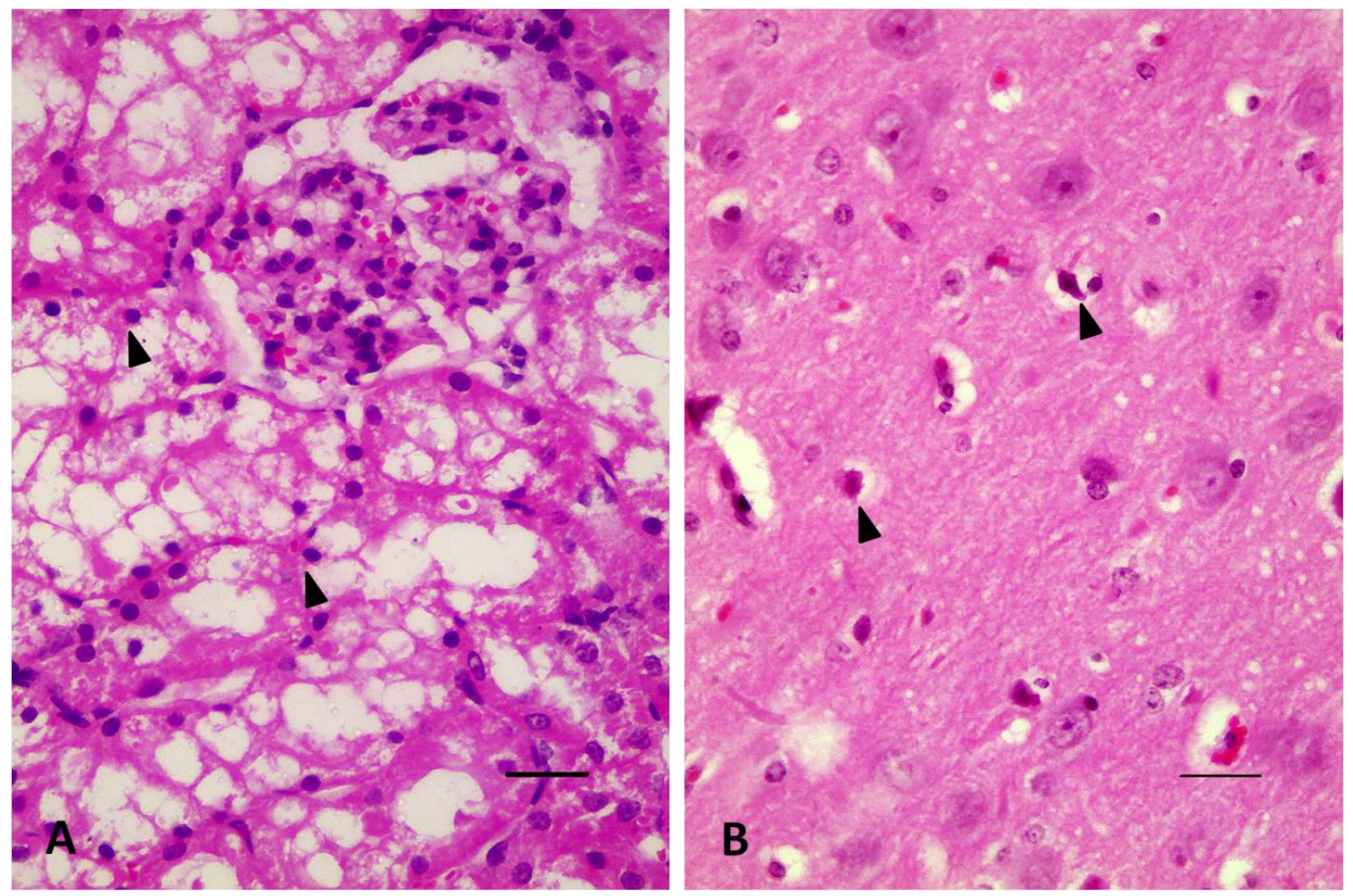

Figura 5. A - Ovino, rim, córtex. Intoxicação crônica por $P$. aeneofusca. Degeneração hidrópicovacuolar de células epiteliais tubulares com focos de cariopicnose (cabeça de seta). HE (barra= $50 \mu \mathrm{m}$ ). B - Ovino, SNC, corpo striatum. Intoxicação crônica por P. marcgravii. Hipereosinofilia e retração neuronal (cabeça de seta). HE (barra= $50 \mu \mathrm{m})$. 